\title{
Replacing Income Taxation with Consumption Taxation in Japan
}

\author{
Gary D. Hansen \\ Department of Economics, UCLA \\ Selahattin Imrohoroglu \\ Marshall School of Business, University of Southern California \\ International Senior Fellow, The Canon Institute for Global Studies
}

※Opinions expressed or implied in the CIGS Working Paper Series are solely those of the author, and do not necessarily represent the views of the CIGS or its sponsor.

※ CIGS Working Paper Series is circulated in order to stimulate lively discussion and comments.

※Copyright belongs to the author(s) of each paper unless stated otherwise. 


\title{
Replacing Income Taxation with Consumption Taxation in Japan*
}

\author{
Gary D. Hansen ${ }^{\dagger}$ and Selahattin İmrohoroğlu
}

October 4, 2017

\begin{abstract}
Over the past two decades, Japan has suffered from low economic growth and a large and growing debt to output ratio. Furthermore, Japan anticipates significant increases in future government expenditures due to an aging population. These problems have led Japan to introduce a consumption tax rate in an attempt to raise revenues, and, more recently, to reduce the statutory corporate income tax rate to raise investment and output growth. In this paper we study the growth and welfare consequences of a reduction in income taxation in Japan along with increases in consumption taxation to stabilize the debt to output ratio. In particular, we consider various unanticipated tax reforms using the model described in Hansen and İmrohoroğlu (2016), We find that while output per working age population is projected to be roughly constant between 2015 and 2021 in the benchmark equilibrium representing the status quo, under alternative policies considered, output could be as much as $15 \%$ higher by 2021.
\end{abstract}

\footnotetext{
* We would like to thank Nao Sudo for comments and suggestions at all stages of this research. The authors also thank the participants of the seminars and conferences at Kyoto University, Universitat Autonoma de Barcelona, Universitat Carlos III de Madrid, University College London, and the Annual Meetings of the Society for Economic Dynamics, Edinburgh.

${ }^{\dagger}$ Department of Economics, UCLA, ghansen@econ.ucla.edu.

${ }^{\ddagger}$ Marshall School of Business, University of Southern California, selo@marshall.usc.edu.
} 


\section{Introduction}

In the last ten to twenty years, policy makers in Japan have continuously grappled with two major policy issues: recovering from low rates of economic growth and achieving fiscal consolidation. Japan's economy has experienced dismal performance since the early 1990s. The rate of growth of real Gross Domestic Product (GDP) was 4.4\% between 1972 and 1990, but has dropped to only 1.0\% between 1991 and 2015. In an influential paper, Hayashi and Prescott (2002) coined the term "the Lost Decade" for the prolonged stagnation during the 1990s. The stagnation has continued until the current years making it the "Lost Decades."1 Partly because large scale fiscal stimulus packages were conducted during the lost decade, Japan's economy has accumulated the highest net debt to output ratio among developed economies. Going forward, the debt to output ratio is expected to further rise due to the projected increase in government expenditures related to the aging of the Japanese society.

Other things being equal, a higher dependency ratio leads to higher expenditures on public health expenditures and pensions, which in turn adds to the fiscal imbalance. Figure 1 displays the predicted time paths of the government purchases and transfer payments relative to GNP2 Both series exhibit a clear positive trend over the next couple of decades.

This paper studies unanticipated changes in tax policy that involve lowering income tax rates (labor income tax rates as well as capital income tax rates) shifting away from income taxation toward consumption taxation. The goal is to study the growth consequences as well as the welfare consequences of such policy reforms. We carry out this analysis using the model developed in Hansen and Imrohoroğlu (2016). In that paper, the implications of policies aimed at reducing Japan's debt to output ratio are studied in an environment without uncertainty-one where economic agents have perfect foresight about future government policy. Here, a similar policy is used to stabilize debt in the long run, but, in addition, unanticipated changes in tax rates are assumed to be introduced at a specified date. What we find is that policies that generate a lot of additional growth in the short run do not necessarily lead to the highest welfare relative to a benchmark case, which is based on the policy studied in Hansen and İmrohoroğlu (2016). In particular, we find that policies that reduce income taxation but postpone increasing consumption taxes until Japan's debt to output ratio reaches some threshold provides lower growth and higher welfare relative to a policy that raises consumption taxes simultaneously with the reduction in income taxes in order to replace lost revenue.

\footnotetext{
${ }^{1}$ As pointed out in Hayashi and Prescott (2002), a slowdown of GDP growth during the 1990s and beyond has come together with a TFP slowdown. Though our paper treats TFP movements as exogenous, given that we focus on implications of changes in tax policy, a good number of economists have explored reasons behind the TFP slowdown. Caballero, Hoshi, and Kashyap (2008) argue that zombie-lending has created stagnation by enabling capital and labor to remain in firms that should instead go bankrupt, leading to lower aggregate productivity than would otherwise be the case. Kwon, Narita, and Narita (2015) use plant level data and find that resource misallocation, labor in particular, contributed negatively to aggregate productivity growth. Guner, Ventura, and Yi (2008) develop a model that delivers an efficient size distribution of firms, and argue that departures from the efficient size distribution lead to lower productivity. Buera, Moll, and Shin (2013) develop a theory in which well-intended policies may have a sizable negative long-run effect on aggregate output and productivity.

${ }^{2}$ These time paths incorporate projections of future government purchases and transfer payments made by Fukawa and Sato (2009) that use detailed information from the Employees Pension Insurance, the National Pension, and the government-managed Health Insurance and Long-term Care Insurance.
} 

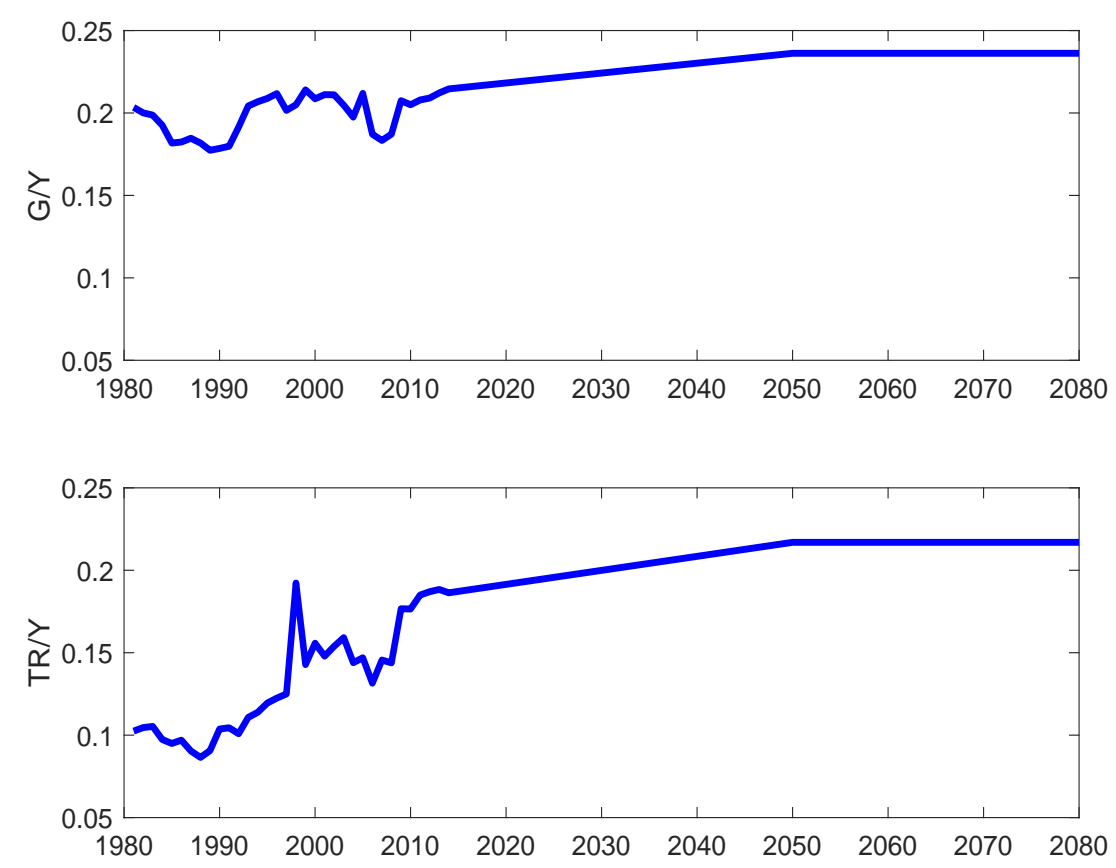

Figure 1: Government Expenditures to GNP: Data 1981-2014, projections 2015-2050

Our motivation is drawn from economic policies that have recently been introduced in Japan to achieve the two policy goals-higher growth and lower debt to output. The Japanese government has launched two economic policy packages independently, each of which involves tax reform. One involves reductions in the corporate tax rate and the other brings about increases in the consumption tax rate. The corporate tax reductions are a part of the policy package known as the "three arrows" proposed by Prime Minister Shinzo Abe in 20133 In fiscal year (FY) 2014, the effective corporate income tax rate was $34.62 \%$. It has since been reduced to $32.11 \%$ with plans for further reductions to $29.97 \%$ in FY 2016/2017 and $29.74 \%$ in FY 2018. The eventual goal is a tax rate of $25 \%$.

The consumption tax in Japan was equal to $5 \%$ from 1997 to 2013. Given projected increases in social security benefits, however, the government announced a "Comprehensive Reform of Social Security and Tax" in 2013, stating that consumption tax rates would be raised eventually to $10 \%$ and the revenues would be secured as financial resources to fund social security. The consumption tax rate was raised from 5\% to $8 \%$ in 2014 as planned, but a further increase from $8 \%$ to $10 \%$ that was scheduled for 2015 was postponed and is now scheduled for 2019. These tax reforms are being implemented independently. On the whole, however, they will change the Japanese tax structure so that it relies more on consumption taxation and less on income taxation.

The model economy we use is a neoclassical growth model built upon Hayashi and Prescott (2002), Chen, Imrohoroğlu, and Imrohoroğlu (2006), and Hansen and Imrohoroğlu (2016). Our model incorporates into an otherwise standard neoclassical growth model two features. The first is that government bond holdings are assumed to provide utility to

\footnotetext{
${ }^{3}$ The "three arrows" consist of monetary easing, fiscal stimulus, and policies designed to increase economic growth. Reductions in the corporate income tax rates belong to the third arrow.
} 
Japanese households. The motivation for this is to account for large domestic holding of Japanese Government Bonds at very low interest rates 4 The second is a debt stabilization policy rule followed by the government. As in Hansen and İmrohoroğlu (2016), once the debt to output ratio reaches a critical level, the Japanese government automatically increases the consumption tax rate to stabilize the debt 5

In contrast to the experiments conducted in Hansen and Imrohoroğlu (2016) in which economic agents have perfect foresight, simulations here are conducted in two steps to reflect the unanticipated nature of the tax reforms studied. First, we compute the equilibrium future time path of endogenous variables including output, tax revenue, and welfare under the hypothetical scenario that no tax reforms are implemented. That is, the tax structure is unchanged from 2014 and beyond. Our simulations take as exogenous inputs forecasts of future government purchases and transfer payments made by Fukawa and Sato (2009) and projections of future population growth rates produced by the Japanese government 6 Taking state variables for 2015 as given from the first step, the second step computes the equilibrium path from 2015 on under the assumption that an unanticipated tax reform is introduced in 2015.

The model-generated equilibrium path indicates that under no tax reform, Japan's economy will continue experiencing stagnant GDP growth and rapid government debt accumulation that quickly exceeds the critical level. When an unexpected elimination of corporate taxes is introduced in 2015 along with an increase in consumption taxes to replace the lost revenue, government debt still reaches the critical level at the same date, but the average annual growth rate of output per person over the following six years is one percent higher than if no reform is introduced. While reducing corporate tax rates is consistent with actual tax reforms proposed in Japan, we also study effects of replacing labor income taxation with consumption taxation for comparison purposes and find that further growth and welfare improvements can be achieved.

Reducing the capital income tax rate, however, jeopardizes fiscal consolidation by reducing tax revenue. In particular, we find that a 3.75 percentage point increase in the the consumption tax rate is needed to replace the lost revenue if the capital income tax rate is reduced to $20 \%$. However, in the long run steady state, the consumption tax is only about 80 basis points higher than it is in our benchmark where there are no reductions in the capital income tax rate other than those Japan has already implemented (a capital income tax rate of $34 \%$ ). If the capital income tax rate is reduced to zero, the steady state consumption tax rate is 2.78 percentage point higher than in the benchmark. On the other hand, reductions in the labor income tax rate would require a much larger increase in the consumption tax to

${ }^{4}$ Sakuragawa and Hosono (2010) employ an alternative approach that incorporates intermediation costs to obtain low equilibrium interest rates on government debt.

${ }^{5}$ In our theoretical model, there is no upper bound to the feasible debt to output ratio. However, we impose an upper bound under the assumption that for reasons not modeled, there is a practical upper bound to this ratio.

${ }^{6}$ Following Hansen and İmrohoroğlu (2016), our simulation incorporates projections made by the National Institute of Population and Social Security Research for the population growth rate, and projections made by Fukawa and Sato (2009) for health insurance and social security benefits that constitute important parts of the government purchases and transfer payments. Admittedly, Japan might choose to renege on the promises to retirees that underlie the forecasts of Fukawa and Sato (2009). However, our analysis will be done under the assumption that these promises will be kept. 
replace lost revenue. A decrease from a labor income tax rate of $33 \%$ in our benchmark to $20 \%$ would require a 13.17 percentage point increase in consumption taxes to replace the lost revenue. In the long run steady state, the consumption tax rate would still be 12 percentage points higher than in the benchmark.

Our paper is closely related to the two strands of the literature on tax structure. Both of them have attracted attention from a large number of macroeconomists over a long period of time. One strand, including Barro (1990), Easterly and Rebelo (1993), and Mendoza, Milesi-Ferretti, and Asea (1997), examines growth implications of tax structure 7 For instance, Barro (1990) theoretically shows that under some conditions income taxation may hamper economic growth. Along the line of his theoretical prediction, recent studies by Knellera, Bleaney, and Gemmell (1999) and Arnold (2008) document using the data of OECD countries that income taxation or property taxation reduces growth while consumption taxation does not. The other strand of literature, including Trabandt and Uhlig (2011), Nutahara (2015), and Hansen and Imrohoroğlu (2016), explores how tax structure matters for fiscal sustainability. Among them, our paper is closest to Hansen and Imrohoroğlu (2016) that studies how much either consumption taxation or labor income taxation must increase to stabilize the growing government debt in Japan.

The structure of this paper is as follows. Section 2 describes the details of our model. Section 3 describes the calibration of the model and the simulation methodology. The results obtained from simulating various tax reforms are presented in Section 4. Section 5 concludes.

\section{Model}

In this section we describe the details of our model, which is similar to the model of Hansen and İmrohoroğlu (2016). The notation employed uses upper case letters to denote variables that are per capita values that grow along a balanced growth path. Lower case letters denote variables that are stationary along a balanced growth path. The time period of the model is one year.

The economy is populated by a representative household with $N_{t}$ members at time $t$. The size of the household is assumed to grow at a time-varying growth factor $\eta_{t}$ so that $N_{t+1}=\eta_{t} N_{t}$.

The fiscal analysis in this paper takes as given time series on tax rates, government spending $\left(G_{t}\right)$, transfer payments $\left(T R_{t}\right)$, the working age population $\left(N_{t}\right)$, and total factor productivity $\left(A_{t}\right)$, where actual time series are used from 1981-2014. Forecasts and assumptions are used to extend these series to 2060 and beyond. In addition, we assume that the tax rates, the ratios of government purchases and transfer payments to output, and the growth rates of $N_{t}$ and $A_{t}$ are all eventually constant and the economy converges to a balanced growth path. Hours worked $\left(h_{t}\right)$, consumption $\left(C_{t}\right)$, output $\left(Y_{t}\right)$, the stock of capital $\left(K_{t}\right)$, tax revenues, government debt $\left(B_{t}\right)$, and the price of government bonds $\left(q_{t}\right)$, from 1981 into the infinite future are endogenously determined by the model.

\footnotetext{
${ }^{7}$ There are also a number of theoretical papers including Judd (1985), Chamley (1986) that study the relationship between the level of output and tax rates.
} 


\section{$2.1 \quad$ Government}

The government is assumed to collect revenue from taxing household consumption at the rate $\tau_{c, t}$, labor income at the rate $\tau_{h, t}$, capital income at the rate $\tau_{k, t}$, and interest on government bonds at the rate $\tau_{b, t}$. Given time series for $G_{t}$ and $T R_{t}$, the quantity of one-period discount bonds $\left(B_{t+1}\right)$ that are issued by the government is determined by the following budget constraint (where all quantities are in per capita terms):

$$
\begin{aligned}
G_{t}+T R_{t}+B_{t}= & \eta_{t} q_{t} B_{t+1}+\tau_{c, t} C_{t}+\tau_{h, t} W_{t} h_{t} \\
& +\tau_{k, t}\left(r_{t}-\delta\right) K_{t}+\tau_{b, t}\left(1-q_{t-1}\right) B_{t} .
\end{aligned}
$$

Here, in addition to variables already defined, $W_{t}$ and $r_{t}$ denote the wage rate and the return to capital, and $\delta$ is the depreciation rate of capital.

The government is also assumed to be subject to a "debt sustainability" rule that forces the government to retire debt when the debt to output ratio reaches some arbitrary value $b_{\max }$ that we specify. We denote the date at which this limit is reached by $T_{1}$. We include this feature for two reasons. First, the solution procedure we use for computing equilibrium paths requires that the economy ultimately converge to a steady state with a constant bond to output ratio. Without some additional constraint, this convergence would not be guaranteed. Second, while there is no natural limit to how much debt the government in our model can issue, such a limit almost certainly exists in actual economies.

Along a given transition path, taxes and transfers are initially determined according to calibrated values. These values may differ across the experiments that we conduct. Once the debt to output ratio hits the threshold level, $b_{\max }$ at $T_{1}$, two fiscal instruments-the level of transfers and the consumption tax rate-become endogenous in order to insure convergence to the terminal steady state that we specify. Denote the initial calibrated values for the consumption tax and transfers for each date $t$ by $\tau_{c, t}^{C}$ and $T R_{t}^{C}$. In addition, denote the value of the consumption tax rate and the debt to output ratio in our steady state by $\bar{\tau}_{c}$ and $\bar{b}$. Given this, the actual values for $\tau_{c, t}$ and $T R_{t}$ are determined as follows:

$$
\begin{gathered}
\tau_{c, t}= \begin{cases}\tau_{c, t}^{C} & \text { if } \left.t<T_{1} \text { (i.e. } B_{s} / Y_{s} \leq b_{\max } \text { for all } s \leq t\right) \\
\bar{\tau}_{c}+\pi & \text { if } T_{1} \leq t<T_{2}\left(\text { i.e. } B_{s} / Y_{s}>b_{\max } \text { for some } s \leq t \text { and } B_{t} / Y_{t}>\bar{b}\right) \\
\bar{\tau}_{c} & \text { if } \left.t \geq T_{2} \text { (i.e. } B_{t} / Y_{t} \leq \bar{b}\right),\end{cases} \\
T R_{t}= \begin{cases}T R_{t}^{C} & \text { if } t<T_{1} \\
T R_{t}^{C}-0.08 Y_{t} & \text { if } T_{1} \leq t<T_{2} \\
T R_{t}^{C}-0.08 Y_{t}-\kappa\left(B_{t}-\bar{b} Y_{t}\right) & \text { if } t \geq T_{2}\end{cases}
\end{gathered}
$$

According to equation (2), once the upper bound on debt is reached, the consumption tax is set equal to its steady state value, $\bar{\tau}_{c}$, plus some constant $\pi$, where $\pi$ is the smallest basis point increase in this tax rate such that the debt to output ratio will begin to decline after date $T_{1}$. Once the debt to output ratio becomes less than or equal to $\bar{b}$, the consumption tax rate is set equal to its steady state value. We denote this date by $T_{2}$. 
In addition, as shown in equation (3), at date $T_{1}$ transfers are reduced by $8 \%$ of output reflecting our assumption that "tax base broadening" will be implemented at the time debtreducing reform is required 8 At date $T_{2}$ transfers are adjusted to retire (or augment) the stock of government debt [determined by equation (1)] so that the debt to output ratio converges to the desired steady state value, $\bar{b}$. Here, $\kappa$ is a positive fraction that determines how quickly the bond to output ratio converges to its steady state value. We use a value of $\kappa=0.1$ in our quantitative exercises.

\subsection{Household's Problem}

The household at time 0 is endowed with initial holdings of per capita physical capital $K_{0}>0$, and real, one-period, zero-coupon, discount bonds $B_{0}$. In addition, each member of the household is endowed with one unit of time each period that can be used for market activities $h_{t}$ or leisure $1-h_{t}$. Given a sequence of wages, rental rates for capital and government bond prices $\left\{W_{t}, r_{t}, q_{t}\right\}_{t=0}^{\infty}$, as well as a sequence of tax rates on consumption expenditures, tax rates on income from labor, capital and holdings of government bonds, and per-capita transfer payments $\left\{\tau_{c, t}, \tau_{h, t}, \tau_{k, t}, \tau_{b, t}, T R_{t}\right\}_{t=0}^{\infty}$, the household chooses a sequence of per member consumption, hours worked, capital, and bond holdings $\left\{C_{t}, h_{t}, K_{t+1}, B_{t+1}\right\}_{t=0}^{\infty}$ to solve the following problem:

$$
\max \sum_{t=0}^{\infty} \beta^{t} N_{t}\left[\log C_{t}-\alpha \frac{h_{t}^{1+1 / \psi}}{1+1 / \psi}+\phi \log \left(\mu_{t+1}+B_{t+1}\right)\right]
$$

subject to

$$
\begin{aligned}
\left(1+\tau_{c, t}\right) C_{t}+\eta_{t} K_{t+1}+q_{t} \eta_{t} B_{t+1}= & \left(1-\tau_{h, t}\right) W_{t} h_{t}+\left[\left(1+\left(1-\tau_{k, t}\right)\left(r_{t}-\delta\right)\right] K_{t}\right. \\
& +\left[1-\left(1-q_{t-1}\right) \tau_{b, t}\right] B_{t}+T R_{t},
\end{aligned}
$$

where $K_{0}>0$ and $B_{0}$ are given initial conditions. The parameter $\beta$ denotes the household's subjective discount factor. The disutility of work is described by $-\alpha<0$ and $\phi>0$ denotes the household's preferences for government bonds. We use $\psi$ to denote the intertemporal elasticity of substitution (IES) of labor.

The household's maximization is subject to a budget constraint [equation (5)] where after-tax consumption expenditures and resources allocated to accumulation of capital and bond holdings are financed by after-tax labor income, after-tax capital income and holdings of capital, after-tax proceeds of bond holdings chosen in the previous period, and transfer payments from the government. Here $K_{t+1}$ and $B_{t+1}$ are per capita holdings of capital and bonds at time $t+1$. $\eta_{t} K_{t+1}$ and $\eta_{t} B_{t+1}$ expresses the same quantities per capita at time $t$.

\footnotetext{
${ }^{8}$ As in Hansen and İmrohoroğlu (2016) we have abstracted from deductions, exclusions, and progressive tax rates that characterize the Japanese tax code. By setting income tax rates equal to the average marginal tax rate in Japan, the amount of revenue raised in our model exceeds that actually raised by the Japanese tax system by $8 \%$ of output. In our basic calibration, we assume this excess revenue is added to transfer payments as a lump sum tax rebate to households. Tax broadening in our context means that we eliminate this tax rebate and allow this revenue to be used to lower the level of debt each period.
} 
Since about $95 \%$ of the Japanese government bonds are held domestically, we assume that Japan is a closed economy where all debt is held by Japanese citizens, i.e. the members of the household in our model. In addition, Japanese government bonds historically have had yields less than the return to physical capital. As a result, we introduce government debt in the utility function, with $\phi>0910$

Finally, $\mu_{t+1}$ is a parameter that limits the curvature of the period utility function over bonds. Essentially, it represents assets that might be perfect substitutes to Japanese government issued bonds in generating utility to households 11 We allow this parameter to move at the same rate of balanced growth as the rest of the economy so that the detrended version is a constant. In particular, $\mu_{t}=\mu A_{t}^{1 /(1-\theta)}$.

\subsection{Firm's Problem}

A stand-in firm operates a constant returns to scale Cobb-Douglas production technology

$$
\begin{aligned}
N_{t} Y_{t} & =A_{t}\left(N_{t} K_{t}\right)^{\theta}\left(N_{t} h_{t}\right)^{1-\theta} \\
N_{t+1} K_{t+1} & =(1-\delta) N_{t} K_{t}+N_{t} X_{t} .
\end{aligned}
$$

Capital depreciates at the rate $\delta$. The income share of capital is given by $\theta$. $A_{t}$ is total factor productivity which grows exogenously at the rate $\gamma_{t}$, so we have $A_{t+1}=\gamma_{t} A_{t}$. Per capita gross investment is denoted by $X_{t}$.

The firm is assumed to hire labor and rent capital from households each period to maximize profits, taking the wage rate $W_{t}$ and rental rate $r_{t}$ as given.

\subsection{Equilibrium}

Given a government fiscal policy $\left\{G_{t}, T R_{t}, B_{t}, \tau_{h, t}, \tau_{k, t}, \tau_{c, t}, \tau_{b, t}\right\}_{t=0}^{\infty}$, a debt sustainability rule $\left\{\kappa, \bar{b}, b_{\max }\right\}$, and the paths of working age population $\left\{N_{t}\right\}_{t=0}^{\infty}$ and technology $\left\{A_{t}\right\}_{t=0}^{\infty}$, a competitive equilibrium consists of an allocation $\left\{C_{t}, h_{t}, K_{t+1}, B_{t+1}\right\}_{t=0}^{\infty}$, factor prices $\left\{W_{t}, r_{t}\right\}_{t=0}^{\infty}$ and the bond price $\left\{q_{t}\right\}_{t=0}^{\infty}$ such that

- the allocation solves the household's problem [equations (41) and (5)],

- the government budget constraint and debt sustainability rule, given by equations (1) - (3), is satisfied each period,

\footnotetext{
${ }^{9}$ For example, consider a simplified version of the model in which the representative household solves $\max \sum_{t=0}^{\infty} \beta^{t}\left\{\log c_{t}+\phi \log b_{t+1}\right\}$ subject to $c_{t}+k_{t+1}+q_{t} b_{t+1}=w_{t}+r_{t} k_{t}+b_{t}+(1-\delta) k_{t}$. The first order conditions are given by $\frac{1}{c_{t}}=\beta \frac{R_{t}}{c_{t+1}}, \frac{\phi}{b_{t+1}}-\frac{q_{t}}{c_{t}}+\frac{\beta}{c_{t+1}}=0$, and $R_{t}=r_{t}+1-\delta$. Steady-state implies $q-\frac{1}{R}=\frac{\phi c}{b}>0$, which means that the return on $k$, denoted by $R$, dominates that on $b$ which is equal to $1 / q$.

${ }^{10}$ While our assumption of bonds providing utility in a neoclassical growth model implies that capital earns a higher return than government debt, it also implies that the optimal quantity of debt is unlimited. Nakajima and Takahashi (2017) studies the optimal debt to output ratio for Japan using a micro-founded model similar to Aiyagari and McGrattan (1998) in which there are both costs and benefits associated with government debt.

${ }^{11}$ This parameter helps us to match the volatility of bond prices.
} 
- the market for bonds clears,

- firms maximize profits and the labor market and capital rental markets clear, which implies that $W_{t}=(1-\theta) A_{t} K_{t}^{\theta} h_{t}^{-\theta}$ and $r_{t}=\theta A_{t} K_{t}^{\theta-1} h_{t}^{1-\theta}$.

- and the goods market clears: $C_{t}+\left[\eta_{t} K_{t+1}-(1-\delta) K_{t}\right]+G_{t}=Y_{t}$,

\subsection{Detrended Equilibrium Conditions}

In this subsection we derive the detrended equilibrium conditions to use in solving the model numerically. Given a trending per capita variable $Z_{t}$ we obtain its detrended per capita counterpart by

$$
z_{t}=\frac{Z_{t}}{A_{t}^{1 /(1-\theta)}} .
$$

The first set of detrended equilibrium conditions is given below.

$$
\begin{aligned}
\frac{\left(1+\tau_{c, t+1}\right) \gamma_{t}^{1 /(1-\theta)} c_{t+1}}{\left(1+\tau_{c, t}\right) c_{t}} & =\beta\left[1+\left(1-\tau_{k, t+1}\right)\left(r_{t+1}-\delta\right)\right], \\
\frac{\phi}{\mu+b_{t+1}}+\frac{\beta \eta_{t}\left[1-\left(1-q_{t}\right) \tau_{b, t+1}\right]}{\left(1+\tau_{c, t+1}\right) c_{t+1}} & =\frac{q_{t} \eta_{t} \gamma_{t}^{1 /(1-\theta)}}{\left(1+\tau_{c, t}\right) c_{t}} \\
\alpha h_{t}^{1 / \psi} & =\frac{\left(1-\tau_{h, t}\right) w_{t}}{\left(1+\tau_{c, t}\right) c_{t}} \\
y_{t} & =k_{t}^{\theta} h_{t}^{1-\theta} \\
\eta_{t} \gamma_{t}^{1 /(1-\theta)} k_{t+1} & =(1-\delta) k_{t}+x_{t} .
\end{aligned}
$$

Equation (6) is the typical Euler equation arising from the choice of capital stock at time $t$. The bond Euler equation is given by (7). The first order condition for hours worked is shown in equation (8). The production function and the law of motion for capital are given in equations (9) and (10), respectively. The budget constraint for the household is given below in equation (11)

$$
\begin{aligned}
& \left(1+\tau_{c, t}\right) c_{t}+\eta_{t} \gamma_{t}^{1 /(1-\theta)} k_{t+1}+q_{t} \eta_{t} \gamma_{t}^{1 /(1-\theta)} b_{t+1} \\
& \quad=\left(1-\tau_{h, t}\right) w_{t} h_{t}+\left[1-\left(1-q_{t-1}\right) \tau_{b, t}\right] b_{t}+t r_{t}+\left[1+\left(1-\tau_{k, t}\right)\left(r_{t}-\delta\right)\right] k_{t} .
\end{aligned}
$$

The government budget equation is given by equation (12)

$$
\begin{aligned}
g_{t}+t r_{t}+b_{t}= & q_{t} \eta_{t} \gamma_{t}^{1 /(1-\theta)} b_{t+1}+\tau_{c, t} c_{t}+\tau_{h, t} w_{t} h_{t} \\
& +\tau_{k, t}\left(r_{t}-\delta\right) k_{t}+\tau_{b, t}\left(1-q_{t-1}\right) b_{t} .
\end{aligned}
$$

Finally, the market clearing conditions are given below in equations (13), (14) and (15)

$$
\begin{aligned}
r_{t} & =\theta k_{t}^{\theta-1} h_{t}^{1-\theta}, \\
w_{t} & =(1-\theta) k_{t}^{\theta} h_{t}^{-\theta}, \\
c_{t}+x_{t}+g_{t} & =y_{t} .
\end{aligned}
$$

Hence we have 9 equations, (6) through (14), in 9 unknowns $\left\{c_{t}, x_{t}, h_{t}, y_{t}, k_{t+1}, b_{t+1}, q_{t}, w_{t}, r_{t}\right\}$ at each time period $t$. 


\subsection{Steady-State Solution}

In this subsection we describe how we compute the steady state equilibrium and how it depends on the experiments we consider in section 4 .

For a variable $z_{t}$, we will denote its steady state value with $\bar{z}$. Also, let $\widehat{z}$ denote $\bar{z} / \bar{y}$, the ratio of $\bar{z}$ to the steady state value of output.

Imposing steady state, equations (6) and (10) become $\widehat{k}=\frac{\beta \theta\left(1-\tau_{k}\right)}{\gamma^{1 /(1-\theta)}-\beta\left[1-\left(1-\tau_{k}\right) \delta\right]}$ and $\widehat{x}=\eta \gamma^{1 /(1-\theta)}+\delta-1$.

Using projections from Fukawa and Sato (2009), we obtain detrended values for $g_{t}$ and $t r_{t}$ and assume that these are constant after 2050. In particular, $\bar{g}=g_{2050}$ and $\overline{t r}=t r_{2050}$.

Given a value for $\overline{\tau_{c}}$, values for $\bar{h}, \widehat{c}$ and $\bar{y}$ are given by $\bar{h}=\left[\frac{(1-\theta)\left(1-\tau_{h}\right)}{\alpha\left(1+\overline{\tau_{c}}\right) \widehat{c}}\right]^{\psi /(1+\psi)}$, $\widehat{c}=1-\widehat{x}-\widehat{g}$, and $\bar{y}=\widehat{k}^{\theta /(1-\theta)} \bar{h}$, where $\widehat{g}=\bar{g} / \bar{y}$.

Using the steady state version of equation (7), we obtain

$$
\bar{q}=\frac{\phi\left(1+\overline{\tau_{c}}\right) \bar{c}+\beta \eta\left(1-\tau_{b}\right) \bar{b}+\mu}{\eta\left[\gamma^{1 /(1-\theta)}-\beta \tau_{b}\right](\mu+\bar{b})}, \text { where } \bar{b}=\widehat{b} \bar{y} .
$$

This plus the steady state version of the government budget constraint (12) can be used to obtain values for $\bar{q}$ and $\overline{\tau_{c}}$. The steady state government budget constraint can be written

$$
\widehat{g}+\widehat{t r}+\left[1-\bar{q} \eta \gamma^{1 /(1-\theta)}\right] \widehat{b}=\bar{\tau}_{c} \widehat{c}+(1-\theta) \tau_{h}+\tau_{k}(\theta-\delta \widehat{k})+\tau_{b}(1-\bar{q}) \widehat{b}
$$

We will assume that the values of $\bar{g}, \overline{t r}, \tau_{b}$ and $\widehat{b}$ are the same across all steady states. However, the income tax rates $\tau_{h}$ and $\tau_{k}$ are different across experiments. As a result, all other aspects of the steady state, including the consumption tax rate $\overline{\tau_{c}}$ and steady state bond holdings $\bar{b}$, will differ across experiments.

\subsection{Solution Procedure}

We take as given a value for $k_{1981}$ and a sequence $\left\{\tau_{h, t}, \tau_{b, t}, \tau_{k, t}, \eta_{t}, \gamma_{t}, g_{t}\right\}_{t=1981}^{\infty}$, where the elements of this sequence are constant beyond some date. These constant values along with $\overline{\tau_{c}}, \bar{g}=g_{2050}$ and $\overline{t r}=t r_{2050}$ determine the steady state to which the economy ultimately converges. We use a shooting algorithm, similar to that in Hayashi and Prescott (2002), Chen, İmrohoroğlu, and İmrohoroğlu (2006) and Hansen and Imrohoroğlu (2016), to determine the value of $c_{1981}$ (or, equivalently, $k_{1982}$ ) such that the sequence of endogenous variables $\left\{c_{t}, x_{t}, h_{t}, y_{t}, k_{t+1}, b_{t+1}, q_{t}, w_{t}, r_{t}\right\}$ determined by equations (6) through (14) converges to the steady state. That is, the shooting algorithm guarantees that the capital stock sequence satisfies the transversality condition. In addition, the fiscal sustainability rule determines the sequence of transfers and consumption taxes, $\left\{t r_{t}, \tau_{c, t}\right\}$, that guarantees that the bond to output ratio is equal to $\widehat{b}$ in the steady state achieved in the limit.

While the above procedure is used to compute our benchmark transition, the primary topic of this paper is to consider the consequences of unanticipated policy changes in 2015. To do this, we first compute the transition path to the steady state for our benchmark calibration. Then, taking $c_{2014}$ (or, equivalently, $k_{2015}$ ) as given, we compute a new 
transition from 2015 to the steady state associated with policy under consideration that was unanticipated prior to 2015. The full transition from 1981 is formed by splicing together the benchmark transition through 2014 with the alternative policy transition beginning with 2015.

\section{Calibration}

The structural parameters of our model are calibrated based on information from the sample period, which consists of annual data from 1981 to 2014. We take the capital-output and bond-output ratios in 1981 as initial conditions and use the sample paths for total factor productivity (TFP), population growth rates, tax rates, government purchases and transfer payments as exogenous inputs to the model. In addition we make assumptions about the values for these exogenous variables beyond the sample period in order to calculate equilibrium transition paths from 1981 toward the eventual steady state.

Population: Our measure of population, $N_{t}$, is working age population between the ages of 20 and 69. What matters for the equilibrium path computed, however, is not the level but the sequence of population growth factors (see equations 6 to 15). We use the actual values between 1981 and 2014 and rely on official projections for 2015-2060. We assume that the population stabilizes by 2080 and implement this by linearly interpolating the last projected value for the gross growth factor, which is 0.9885 , to converge to 1.0 by 2080 . That is $\eta_{t}=1, t \geq 2080$. The projections for 2015 -2060 are the medium-fertility and mediummortality variants of population forecasts calculated by the National Institute of Population and Social Security Research.

National Accounts: Our measure of output is real Gross National Product adjusted to include income from foreign capital, following Hayashi and Prescott (2002). In particular, we define the model's capital stock, $K_{t}$, as consisting of private fixed capital, held domestically and in foreign countries. We add net exports and net factor payments from abroad to measured private investment.

Government investment, including net land purchases, is assumed to be expensed. Therefore we treat it as part of government consumption and subtract depreciation of government capital from government consumption. We summarize these choices in Table 1 . 
Table 1: Adjustments to National Account Measurements

\begin{tabular}{ll}
\hline$C=$ & Private Consumption Expenditures \\
$I=$ & Private Gross Investment \\
& $\quad+$ Change in Inventories \\
& + Net Exports \\
& $\quad+$ Net Factor Payments from Abroad \\
$G=\quad$ & Government Final Consumption Expenditures \\
& + General Government Gross Capital Formation \\
& + Government Net Land Purchases \\
& $\quad$ Book Value Depreciation of Government Capital \\
\hline$Y=$ & $C$
\end{tabular}

Labor input: For $h_{t}$ we take the product of employment per working age population and average weekly hours worked, normalized by dividing by 98 , which is our assumption on discretionary hours available per week.

Government Accounts: Our measure of government purchases of goods and services, $G_{t}$ in Table 1, also includes Japanese public health expenditures. Transfer payments, $T R_{t}$, includes social benefits (other than those in kind, which are included in $G_{t}$ ) that are mostly public pensions, plus other current net transfers minus net indirect taxes. We add $8 \%$ of output to our measure of transfers since our modeling of flat tax rates leads to higher tax revenue than in the data because we abstract from all deductions and exemptions that are present in the complicated Japanese tax code. That is, the tax revenue collected minus the $8 \%$ of output corresponds to the actual tax revenue collected by the government.

As we mentioned in the Introduction (see Figure 1), Japan's already high debt to output ratio is projected to rise even further due to the aging of the population. Fukawa and Sato (2009) estimate an increase of 3 percentage points in the ratio of government purchases to output and a 4 percentage point rise in transfer payments to output from 2010 to 2050. According to Fukawa and Sato (2009), the projected increase in government purchases is nearly entirely due to the expected increase in public long term care expenditures, driven by the increased longevity of the population. Similarly, the projected increase in transfer payments are driven by expected increases in public pension expenditures 12 These estimates are very similar to those calculated independently by İmrohoroğlu, Kitao, and Yamada $(2016) 13$

\footnotetext{
${ }^{12}$ The projections in Fukawa and Sato (2009) are based on a system of about 40 regression equations (in addition to definitional relations and equations describing the evolution of the population in different age groups) which is estimated from Japanese data sources over the sample period 1980-2003. The population projections used are the same as those used in this paper. In addition, they assume a rate of growth of real GDP of about $2 \%$.

13 İmrohoroğlu, Kitao, and Yamada (2016) build a micro-data based large-scale overlapping generations
} 
Our calibration of the projected increase in government purchases and transfer payments combine the Fukawa and Sato (2009) estimates with the realized values for 2010-2014. In particular, given the actual 2010 values for $G / Y$ and $T R / Y$, we use Fukawa and Sato (2009) projections to obtain the 2050 ratios. Then, we use the observed ratios for 2010-2014 and linearly interpolate the ratios to 2050. This leads to increases of 2.06 and 3.06 percentage points in $G / Y$ and $T R / Y$, respectively, from 2015 to 2050 . Given that output is endogenous in our model, we obtain the levels of $G$ and $T R$ from the benchmark model in Hansen and İmrohoroğlu (2016) and use the same sequences of these expenditures in all experiments.

Tax Rates: Our measure of labor income tax rates, $\tau_{h, t}$, for 1981-2014, comes from the estimates of average marginal labor income tax rates by Gunji and Miyazaki (2011). The last value is 0.3324 for 2007 and we assume that this same value holds for 2008 and beyond in the benchmark calibration.

The capital income tax rate, $\tau_{k, t}$, is constructed following the methodology in Hayashi and Prescott (2002). The value of this tax rate for 2014 is 0.3409 which is assumed to be unchanged in the benchmark equilibrium transition.

In alternative transitions, the income tax rates, $\tau_{h, t}$ or $\tau_{k, t}$ or both will change exogenously at part of a tax reform package.

A consumption tax rate of $\tau_{c, t}=3 \%$ was introduced in Japan in 1989, and it was raised to $5 \%$ in 1997 and to $8 \%$ in 2014 . It is scheduled to rise to $10 \%$ in 2019 . In all our experiments, we keep the consumption tax rate at $8 \%$ beyond 2014 and allow this tax rate to endogenously rise to a value consistent with fiscal sustainability given our assumptions on the debt to output ratio in the final steady state.

The tax rate on interest from government bonds, $\tau_{b, t}$, is equal to $20 \%$ for all time periods. This tax is imposed on the interest income from coupon-bearing bonds and is withheld ( $15 \%$ income tax plus $5 \%$ local tax) at the time the interest is paid.

Figure 2 shows the tax rates used except for the tax on bond interest income, which is constant throughout at $20 \%$.

Technology parameters: Given the data described above, the Cobb-Douglas production function allows us to calculate total factor productivity:

$$
A_{t}=Y_{t} /\left(K_{t}^{\theta} h_{t}^{1-\theta}\right)
$$

The capital income share, $\theta$, is set equal to 0.3798, which is the sample (1981-2014) average of the annual ratio of capital income to our adjusted measure of GNP. Given this, we can compute the growth factor of TFP, $\gamma_{t}=A_{t+1} / A_{t}$, from the actual data between 1981 and 2014. For 2015 and beyond, we assume that $\gamma_{t}=1.015^{1-\theta}$. This implies a growth rate of $1.5 \%$ for per capita output along the balanced growth path. Finally, we compute a time series for the depreciation rate of capital following the methodology of Hayashi and Prescott (2002) and set $\delta=0.0816$, which is the sample average.

model for Japan and incorporate the Japanese pension rules in detail. Using existing pension law and fiscal parameters and the medium variants of fertility and survival probability projections, they produce future time paths for government purchases and transfer payments. 


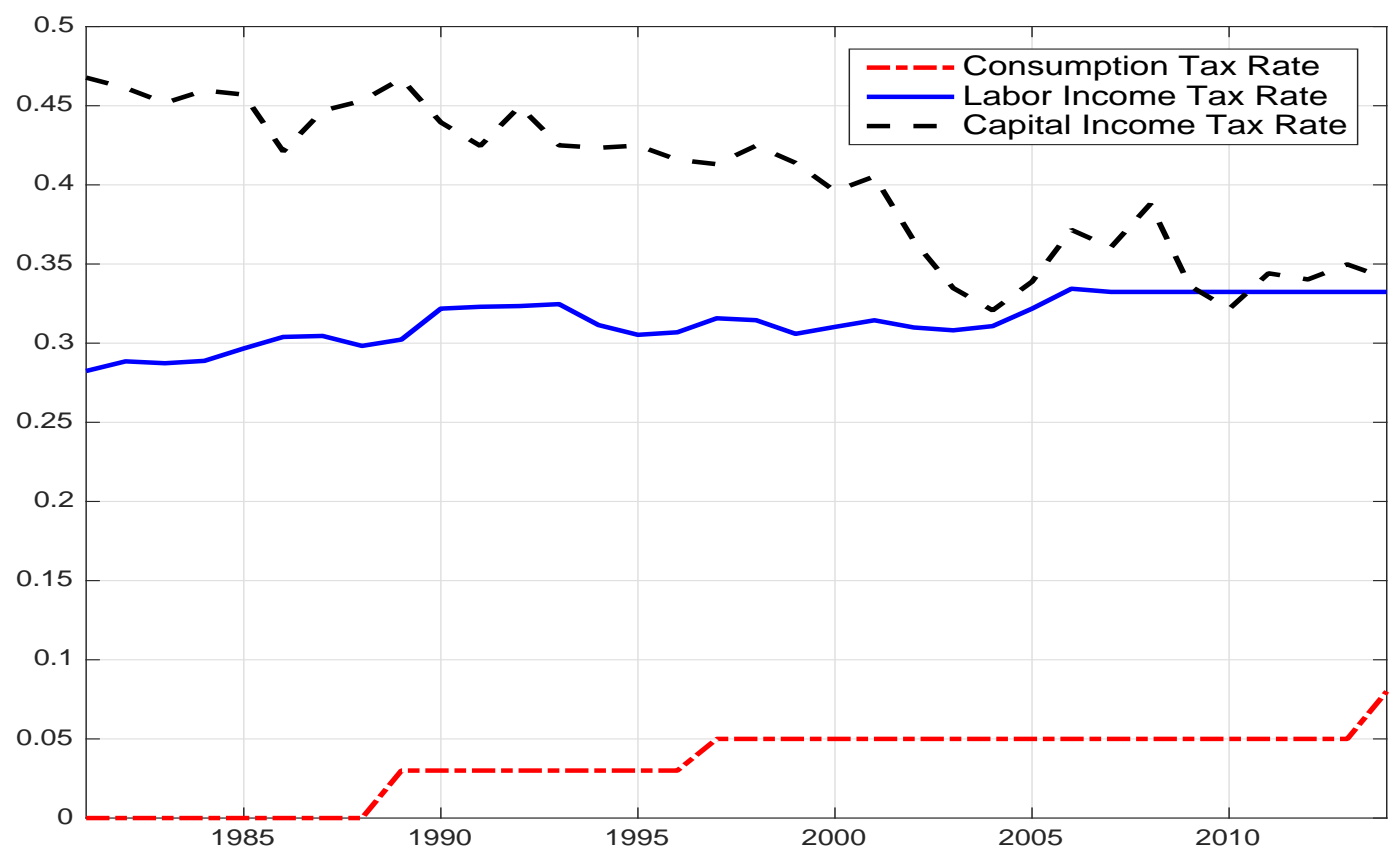

Figure 2: Tax Rates

The working-age population growth factors are taken from the data for the sample period of 1981-2014. For 2015-2060, we take the population projections by the government projections consistent with their medium fertility, medium mortality projections. This implies a working-age population growth factor of 0.9885 for 2059 . We assume that the growth factors linearly converge to 1.0 in 20 years so that the working-age population is stationary from 2099.

Preference parameters: There are five preference parameters, $\beta, \alpha, \psi, \phi$, and $\mu$, in the utility function given by equation (44), where $\mu=\mu_{t} / A_{t}^{1 /(1-\theta)}$. These are held constant throughout our analysis. The parameter $\psi$ is the Frisch elasticity of labor supply, taken as 0.5, following Chetty, Guren, Manoli, and Broda (2012).

For the three preference parameters $\beta, \alpha$, and $\phi$, we use the equilibrium conditions given in equations (16), (17), and (18) for the sample period to obtain values for each year and, from that, averages over the sample. 
Table 2: Calibration of Structural Parameters

\begin{tabular}{lll}
\hline Parameter & Value & \\
\hline$\theta$ & 0.3798 & Sample Average, 1981-2014 \\
$\delta$ & 0.0816 & Sample Average, 1981-2014 \\
$\beta$ & 0.9680 & Equation (16)), Sample Average \\
$\alpha$ & 22.03 & Equation (17), Sample Average \\
$\psi$ & 0.5 & Chetty et al (2012) \\
$\phi$ & 0.12 & Equation (18) , Sample Average \\
$\mu$ & 1.1 & Fit $q_{t}$ for 1981-2014 \\
\hline
\end{tabular}

$$
\begin{aligned}
\beta_{t} & =\frac{\left(1+\tau_{c, t+1}\right) \gamma_{t}^{1 /(1-\theta)} c_{t+1}}{\left(1+\tau_{c, t}\right) c_{t}\left[1+\left(1-\tau_{k, t+1}\right)\left(\theta \frac{y_{t+1}}{k_{t+1}}-\delta\right)\right]} \\
\alpha_{t} & =\frac{h_{t}^{-1 / \psi}\left(1-\tau_{h, t}\right)(1-\theta) y_{t}}{\left(1+\tau_{c, t}\right) c_{t} h_{t}} \\
\phi_{t} & =\eta_{t}\left(\mu+b_{t+1}\right)\left[\frac{q_{t} \gamma_{t}^{1 /(1-\theta)}}{\left(1+\tau_{c, t}\right) c_{t}}-\frac{\beta_{t}\left[1-\left(1-q_{t}\right) \tau_{b, t+1}\right]}{\left(1+\tau_{c, t+1}\right) c_{t+1}}\right] .
\end{aligned}
$$

Note, however, that the equilibrium condition in equation (18) contains the equilibrium price of government bonds, $q_{t}$. The empirical counterpart to $q_{t}$ that we compute reflects the fact that government debt in actual economies is comprised of bond holdings of varying maturities while our model economy includes only one period discount bonds. In particular, let $B_{t}$ be beginning of period debt and $P_{t}$ be interest payments made in period $t$, both measured in current Yen. In addition, let $F_{t}$ be the GNP deflator. We compute the price of bonds in period $t$ as follows:

$$
q_{t}=\frac{B_{t+1} / F_{t}}{\left(B_{t+1}+P_{t+1}\right) / F_{t+1}} .
$$

Using data on $B_{t+1}, F_{t}$, and $P_{t+1}$ over the sample period, we compute $q_{t}$ and feed the values into the equilibrium conditions above to calculate the sample values of the preference parameters.

The remaining preference parameter $\mu$, which is the detrended value of $\mu_{t}$, is chosen to minimize the sum of squared differences between the bond price implied by our model and its data counterpart.

Table 2 reports the values for the structural parameters.

Fiscal rule parameters: We now describe how we choose the parameters that govern the fiscal sustainability rule introduced earlier in equation (2). For $b_{\max }$, the maximum net debt to output ratio beyond which fiscal austerity kicks in, we use $250 \%$. Although this value may 
seem too high for most advanced economies, for Japan, it may be more reasonable. Indeed, the (net) debt to output ratio for 2015 is already around $150 \%$. In addition, setting $b_{\max }$ equal to $250 \%$ is consistent with the maximum sustainable debt to output ratio estimated by Hoshi and Ito (2014).

We assume that in all our experiments, the debt to output ratio along the balanced growth path, $\widehat{b}$, is equal to $200 \%$. We do not have a strong argument for what this parameter may be in the long run. However, in earlier work, Hansen and Imrohoroğlu (2016) conducted a sensitivity analysis over various values of $\widehat{b}$ and found that this parameter had very little effect on the short run analysis which we are trying to emphasize in this paper.

As mentioned earlier, $\pi$ in equation 2 is set equal to the smallest value such that additional revenue creation leads to debt retirement at date $T_{1}$ and guarantees convergence to $\widehat{b}$, together with $\kappa$ in equation 3 set to 0.1 . The value of $\kappa$ is the same in all our experiments, but $\pi$ is specific to each experiment.

\section{Quantitative Experiments}

\subsection{Steady State Tradeoffs}

Figure 3 shows the steady state tradeoff between using a capital tax $\left(\tau_{k}\right)$ versus a consumption $\operatorname{tax}\left(\tau_{c}\right)$ to raise a given constant amount of revenue holding the labor tax rate constant 14 In this figure, the labor tax rate is held constant at the calibrated level for years beyond $2014\left(\tau_{h}=0.3324\right)$. The fact that this curve is quite flat near the calibrated value for $\tau_{k}$ (the veridical line in figure) means that it is possible to reduce the capital tax rate without raising the consumption tax by much.

Similarly, Figure 4 shows the same steady state tradeoff between the consumption tax rate and the labor income tax rate, holding $\tau_{k}$ at the calibrated level. In this case, the tradeoff between consumption taxation and income taxation is much steeper. In particular, a ten percent decrease in the labor income tax rate would require about a ten percent increase in the consumption tax rate in order to hold revenue constant.

While these steady state tradeoffs are illustrative, they provide no information as to the desirability of a policy change moving from income taxation to consumption taxation. In order to do this, we consider the welfare consequences of a such a change taking into account the transition that such a policy change would initiate. This is done in the next subsection.

\subsection{Short Run Analysis}

In this section we consider two different ways of implementing a policy that reduces income taxes beginning in 2015. In the first set of experiments, the consumption tax rate is assumed to rise at the beginning of 2015 in order to replace the lost revenue associated with the reduction in income tax rates. This means that more time will pass before the debt to output trigger in equation (2) is reached. We label this experiment as 'revenue-neutral'. In

\footnotetext{
${ }^{14}$ Note that by holding revenue constant we actually mean holding the revenue raised by labor, capital and consumption taxation constant. The revenue from taxing the interest on government debt is affected slightly due to general equilibrium effects.
} 


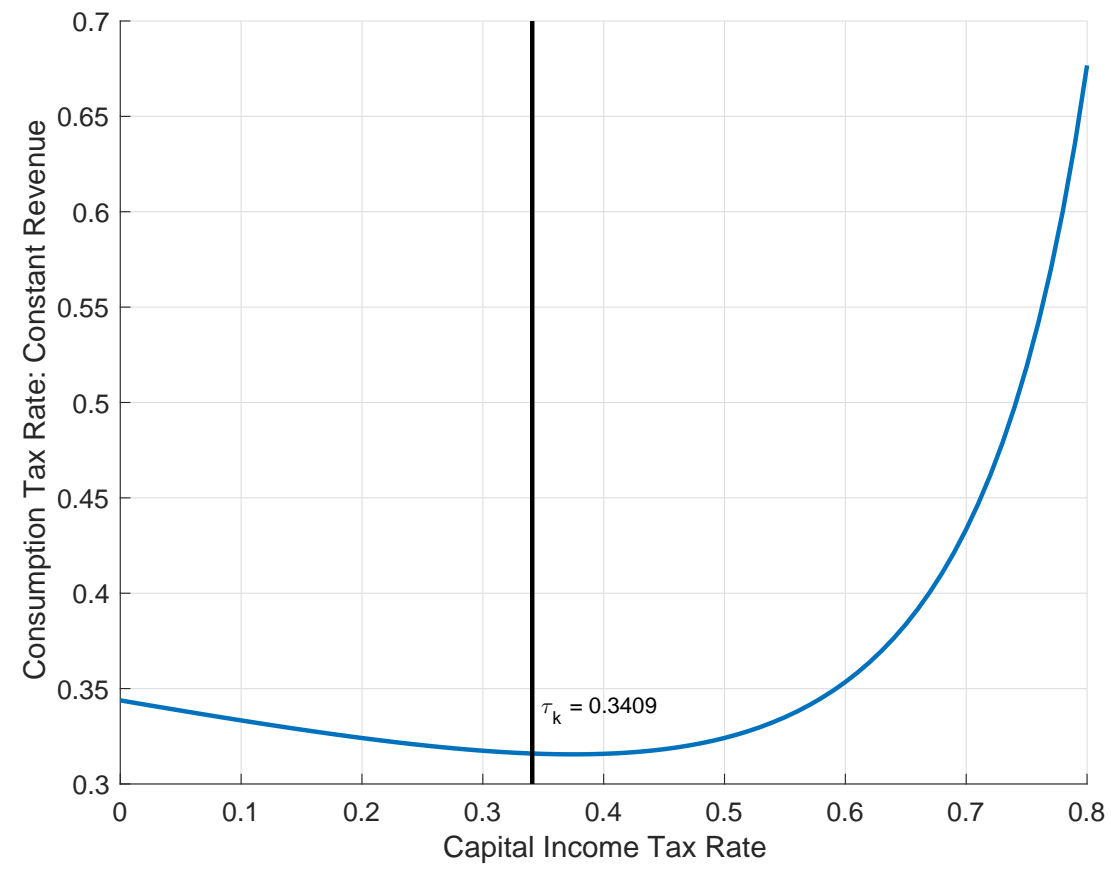

Figure 3: Steady State Iso-Revenue Curve $\left(\tau_{h}=0.3324\right)$

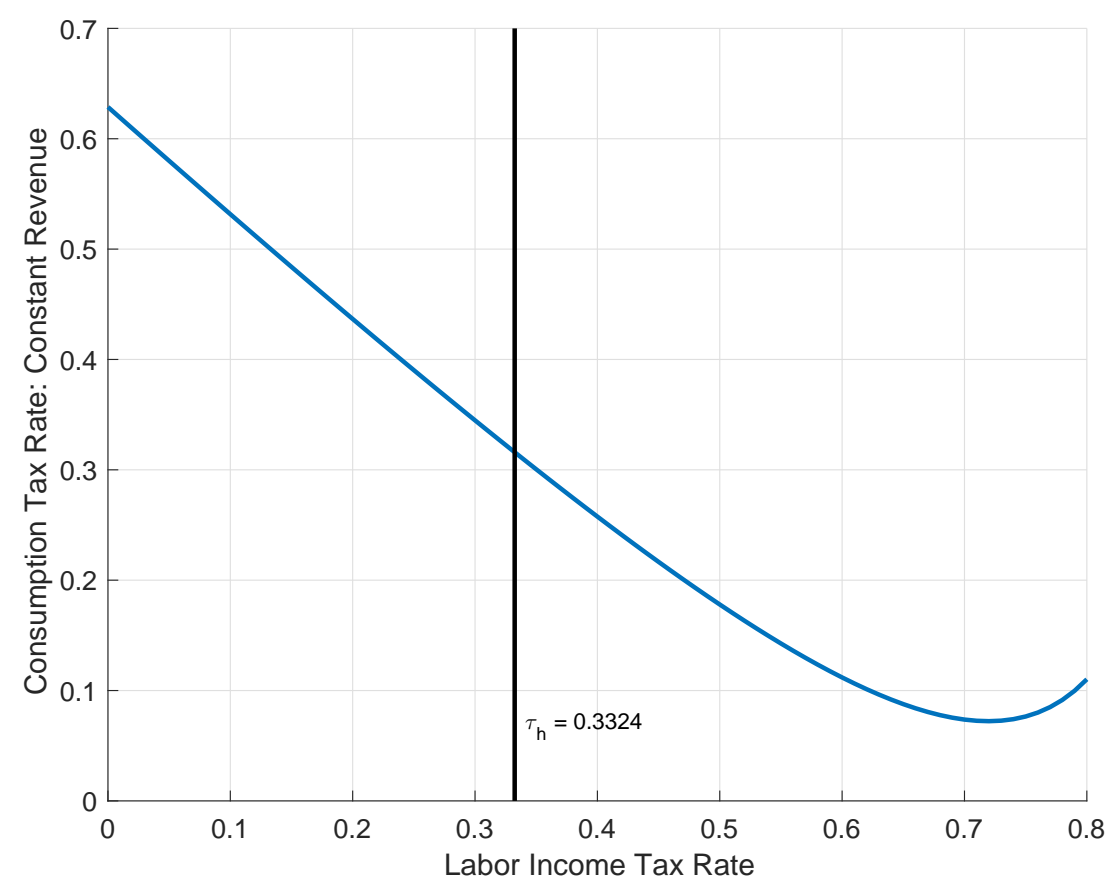

Figure 4: Steady State Iso-Revenue Curve $\left(\tau_{k}=0.3409\right)$ 
Table 3: Experiments

\begin{tabular}{lll}
\hline & \multicolumn{2}{l}{ For $t \geq 2015$} \\
& $\tau_{k, t}$ & $\tau_{h, t}$ \\
\hline$E 1$ & 0.3409 & 0.3324 \\
$E 2$ & 0.20 & 0.3324 \\
$E 3$ & 0.0 & 0.3324 \\
$E 4$ & 0.3409 & 0.20 \\
$E 5$ & 0.3409 & 0.0 \\
$E 6$ & 0.20 & 0.20 \\
$E 7$ & 0.0 & 0.0 \\
\hline
\end{tabular}

the second set of experiments, no increase in the consumption tax is implemented in 2015. We call this experiment 'delayed increase', in which the government is assumed to delay the increase in the consumption tax rate until the debt to output trigger $b_{\max }$ is reached. At this point, as in our benchmark calibration, it is assumed that the Japanese government must respond in some way to reduce the debt to output ratio. In particular, in our benchmark calibration it does so by increasing $\tau_{c}$.

For each of these two approaches, seven policy scenarios are considered. The first, which we label E1, is the same in both cases. This is our benchmark calibration in which there is no reduction in income tax rates and the consumption tax is increased once debt to output reaches $b_{\max }$. The other experiments are ones where $\tau_{k}$ and/or $\tau_{h}$ are reduced in 2015. Table 3 summarizes these experiments.

\subsubsection{How the Model's Rule for Fiscal Sustainability Works}

In this subsection, we describe how our rule works to achieve fiscal sustainability in our benchmark transition. In alternative transition paths, the rule works in a similar fashion with slightly different parameters that again are selected to ensure convergence to the final steady state.

Until 2015, the economy moves along under the expectation that the tax system will not change except for the use of a higher consumption tax rate when the debt to output ratio exceeds 250\%. Figure 5 indicates that the first trigger, $T_{1}$ occurs in the year 2020 in this benchmark equilibrium transition E1. The consumption tax rate rises from $8 \%$ to $37.6 \%$ in order to begin to process of accumulating sufficient tax revenue to pay for the increasing public expenditures and to retire a fraction of the outstanding debt toward its steady state level. After decades of raising significant revenue, once the public expenditures stabilize in 2050 and sufficient debt is retired so that the debt to output is on its path to its steady state level of $200 \%$, the second trigger occurs in 2084 and the consumption tax rate falls to its steady state level of $31.6 \%$. We can now proceed to describe the short run quantitative findings in experiments E2 through E7. 


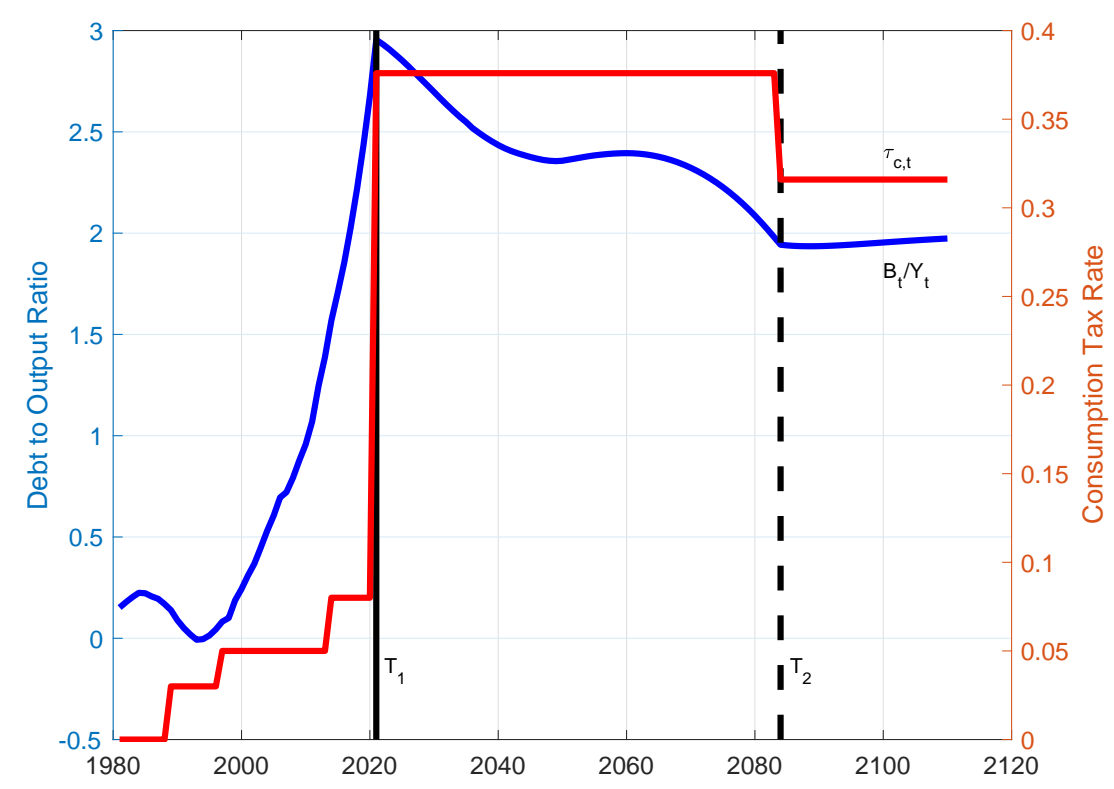

Figure 5: Debt to Output Ratio and the Consumption Tax Rate

\subsubsection{Unanticipated Reform with a Revenue-Neutral Increase in $\tau_{c}$}

In experiments $\mathrm{E} 2$ through $\mathrm{E} 7, \tau_{c}$ is increased in 2015 to replace the lost revenue from reducing income tax rates in that year. In particular, Table 4 summarizes what happens in each of these cases. In particular, the table indicates what happens to the consumption tax rate, as well as the effective tax rate, in 2015 15 In addition, the changes in these tax rates at the two key dates, $T_{1}$ and $T_{2}$, are also indicated. Recall that $T_{1}$ is the first date at which the debt to output ratio exceeds $b_{\max }$ and $T_{2}$ is the first date that the debt to output ratio falls below $\bar{b}$ [see equation (22)]. At $T_{2}$ the consumption tax rate (and hence the effective tax rate) is set equal to its steady state value.

In experiments E2 and E3 the capital tax rate is lowered in 2015. The increase in $\tau_{c}$ needed to keep revenue constant is shown in the first row of the table. The next increase in $\tau_{c}$ is at date $T_{1}$. This happens in 2021 in the benchmark (E1) as well as in E2 and E3. Once this tax increase is in place, the debt to output ratio begins to fall. Once it falls below $\bar{b}$, at date $T_{2}$, the consumption tax rate is decreased to its steady state value. This happens in 2084 in the benchmark case, 2088 in E2 and 2109 in E3.

Next, experiments E4 and E5 show the tax changes that occur when only $\tau_{h}$ is decreased. As the table shows, a larger increase in the consumption tax is required in 2015 in order to compensate for the revenue lost from reducing $\tau_{h}$ than was required when reducing $\tau_{k}$ by the same amount. This matches what might be expected given the steady state results discussed previously. However, the effective tax rate actually falls when $\tau_{h}$ is decreased and $\tau_{c}$ increased in 2015. That is, while the consumption tax rate is increased in 2015, the distortion caused by labor/consumption taxation actually falls.

Finally, in experiments E6 and E7 both $\tau_{k}$ and $\tau_{h}$ are lowered in 2015. As expected,

\footnotetext{
${ }^{15}$ The effective tax rate measures the total tax distortion in the first order condition for labor [equation [8] ]. In particular the effective tax rate is given by $\tau$, where $1+\tau=\frac{1-\tau_{h}}{1+\tau_{c}}$.
} 
Table 4: Unanticipated Reform with a Revenue-Neutral Increase in $\tau_{c}$

\begin{tabular}{|c|c|c|c|c|c|c|c|}
\hline & $E 1$ & $E 2$ & $E 3$ & $E 4$ & $E 5$ & E6 & E7 \\
\hline$\tau_{c, 2015}$ & 0.08 & 0.1175 & 0.1708 & 0.2117 & 0.4108 & 0.2493 & 0.5016 \\
\hline$\tau_{2015}$ & 0.3818 & 0.4026 & 0.4298 & 0.3398 & 0.2912 & 0.3596 & 0.3340 \\
\hline$T_{1}$ & 2021 & 2021 & 2021 & 2021 & 2022 & 2021 & 2021 \\
\hline$\tau_{c, T_{1}}$ & 0.3760 & 0.3941 & 0.4238 & 0.4667 & 0.6487 & 0.4985 & 0.7152 \\
\hline$\tau_{T_{1}}$ & 0.5148 & 0.5211 & 0.5311 & 0.4546 & 0.3935 & 0.4661 & 0.4170 \\
\hline$T_{2}$ & 2084 & 2088 & 2109 & 2100 & 2106 & 2078 & 2141 \\
\hline$\tau_{c, T_{2}}$ & 0.3160 & 0.3241 & 0.3438 & 0.4367 & 0.6287 & 0.4485 & 0.6752 \\
\hline$\tau_{T_{2}}$ & 0.4927 & 0.4958 & 0.5032 & 0.4432 & 0.3860 & 0.4477 & 0.4031 \\
\hline \multicolumn{8}{|c|}{$E 1:$ Benchmark, $\tau_{k, t}=0.3409$ and $\tau_{h, t}=0.3324$ for all $t \geq 2015$} \\
\hline \multicolumn{8}{|c|}{$E 2: \tau_{k, t}=0.2$ and $\tau_{h, t}=0.3324$ for all $t \geq 2015$} \\
\hline \multicolumn{8}{|c|}{$E 3: \tau_{k, t}=0$ and $\tau_{h, t}=0.3324$ for all $t \geq 2015$} \\
\hline \multicolumn{8}{|c|}{$E 4: \tau_{k, t}=0.3409$ and $\tau_{h, t}=0.2$ for all $t \geq 2015$} \\
\hline \multicolumn{8}{|c|}{$E 5: \tau_{k, t}=0.3409$ and $\tau_{h, t}=0$ for all $t \geq 2015$} \\
\hline \multicolumn{8}{|c|}{$E 6: \tau_{k, t}=0.2$ and $\tau_{h, t}=0.2$ for all $t \geq 2015$} \\
\hline \multicolumn{8}{|c|}{$E 7: \tau_{k, t}=0$ and $\tau_{h, t}=0$ for all $t \geq 2015$} \\
\hline \multicolumn{8}{|c|}{$T_{1}$ : Date when $B / Y$ reaches $250 \%$} \\
\hline \multicolumn{8}{|c|}{$T_{2}$ : Date when $B / Y$ is less than or equal to steady state value. } \\
\hline \multicolumn{8}{|c|}{$\tau_{c, t}:$ Consumption tax rate at date $t$} \\
\hline \multicolumn{8}{|c|}{$\begin{array}{l}\tau_{t}=\left(\tau_{c, t}+\tau_{h, t}\right) /\left(1+\tau_{c, t}\right) \text { Effective tax rate at date } t . \\
\pi \text { in equation (2) equals } \tau_{c, T_{1}}-\tau_{c, T_{2}} .\end{array}$} \\
\hline
\end{tabular}

the change in $\tau_{c}$ required in 2015 is larger than in the cases where only one tax rate is lowered. In fact, the required increase in experiment E7 (both $\tau_{k}$ and $\tau_{h}$ reduced to zero), is equal to the sum of the increases seen in experiments E3 (only $\tau_{k}$ reduced to zero) and E5 (only $\tau_{h}$ reduced to zero). In particular, $\tau_{c}$ is increased by $9.08 \%$ in experiment E3, by $33.08 \%$ in E5, and by $42.16 \%$ in E7. A similar results holds for experiments E2, E4 and E6 where the tax rates on labor and capital are lowered to 0.2 rather than zero.

The transition paths for the capital stock, hours worked, and output are shown in Figures 6 through 8. In particular, we compare the transitions for the benchmark case (E1), the case where the capital tax rate is set equal to zero in 2015 (E3), the case where the labor tax rate is set equal to zero in 2015 (E5) and the case where both tax rates are set equal to zero.

Figure [6] shows that capital stock is slightly above the benchmark path when only $\tau_{h}$ is set to zero, but is significantly higher when $\tau_{k}$ is set to zero in experiments E3 and E7. Conversely, hours worked is not much affected by only setting $\tau_{k}$ equal to zero, as shown in Figure 7, but is increased substantially when $\tau_{h}$ is set to zero in E5 and E7.

The paths for output, shown in Figure 8, incorporates changes in both inputs to production. All policy changes shown increase output relative to the benchmark. Setting both tax rates to zero (E7) increases output the most while only setting $\tau_{h}$ to zero (E5) increases it the least. 


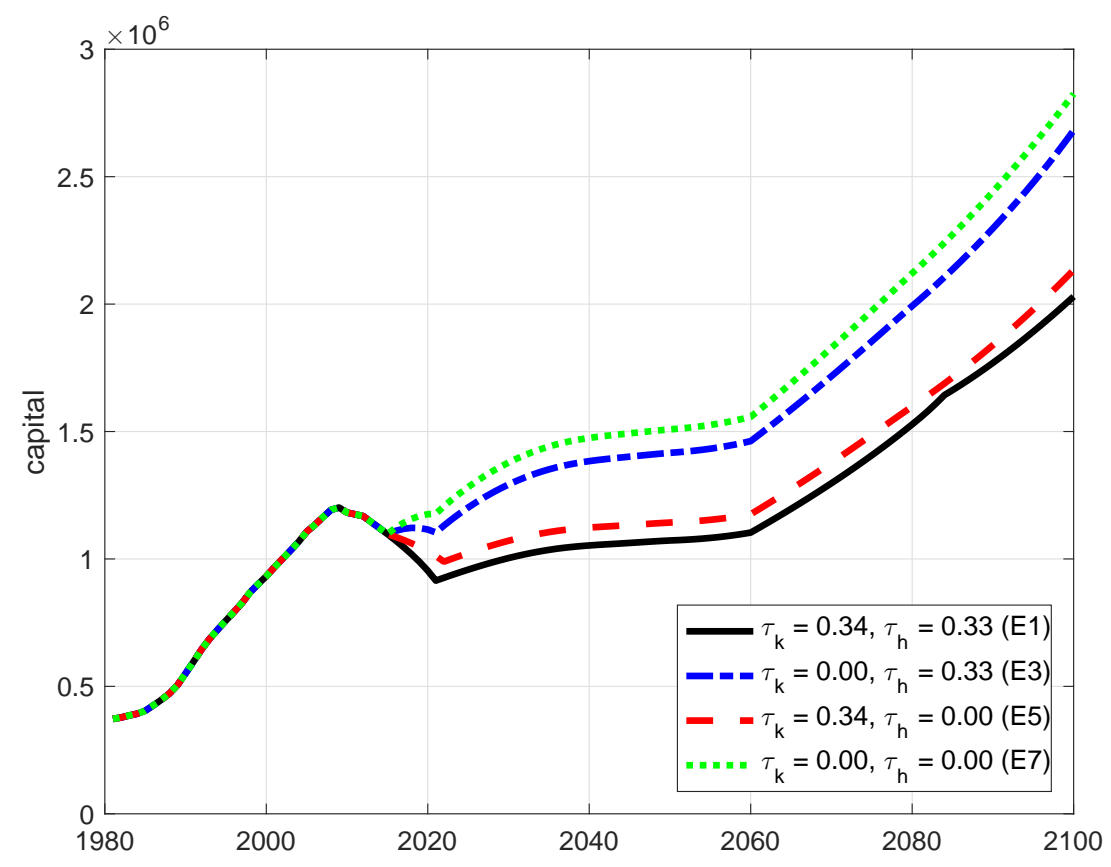

Figure 6: Capital Stock

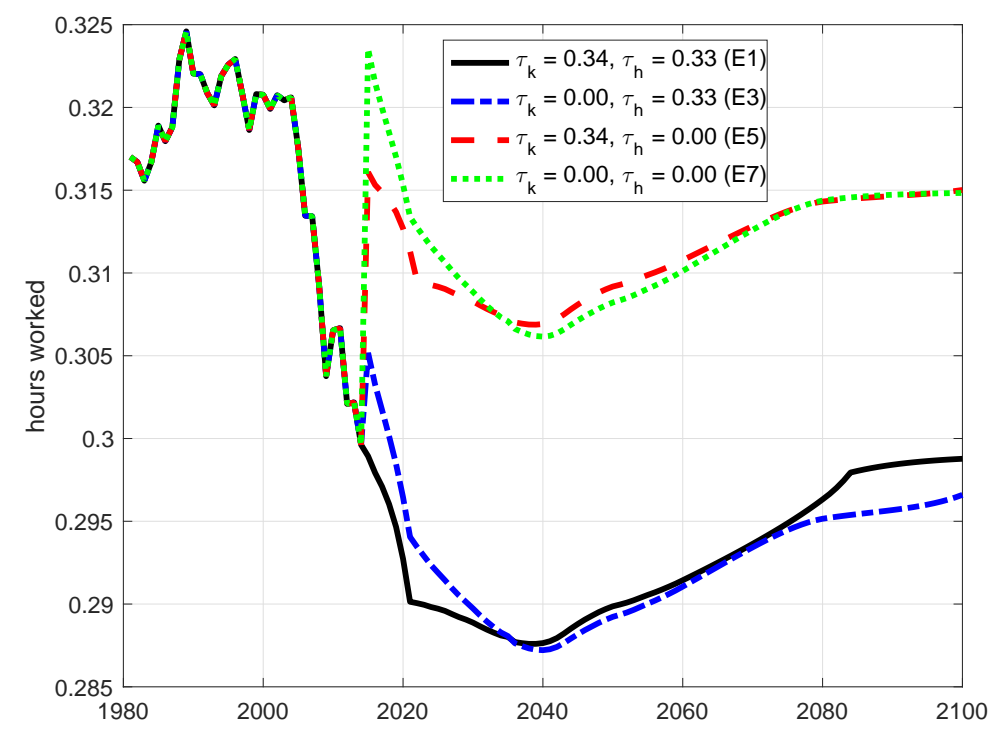

Figure 7: Hours Worked 


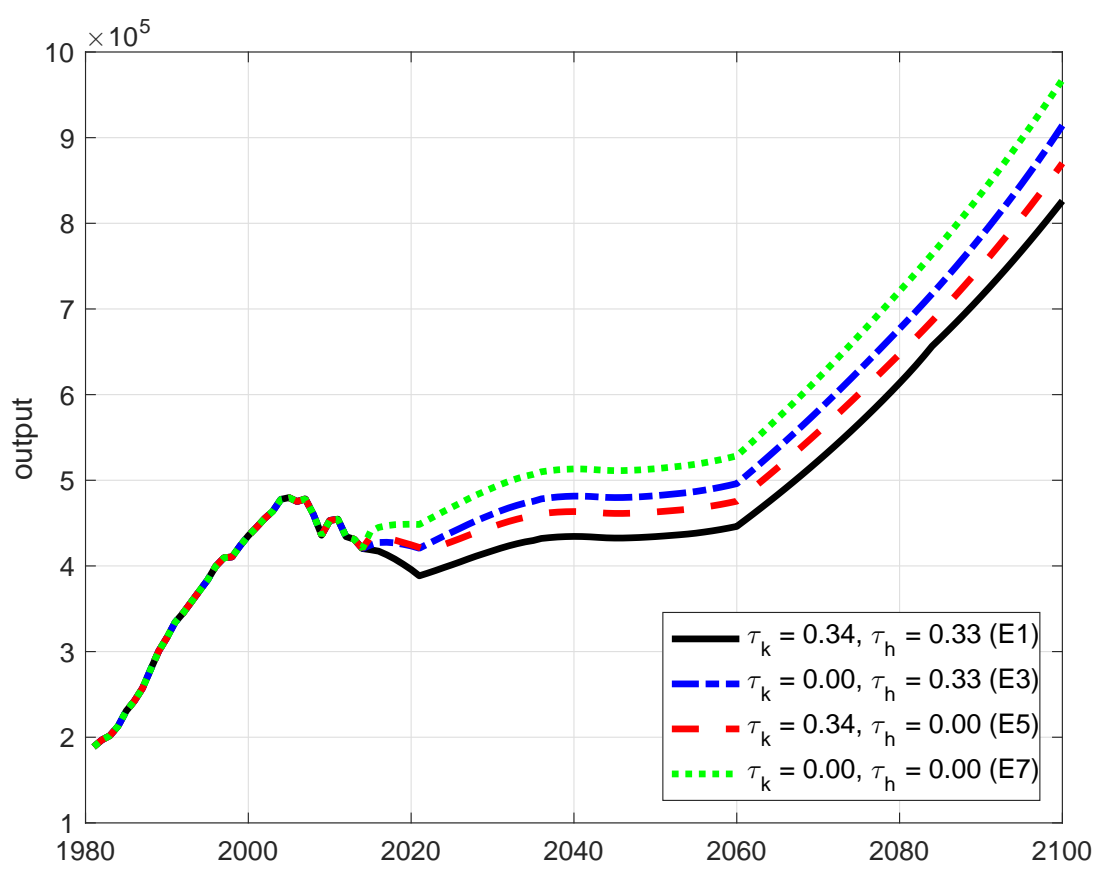

Figure 8: Output

Table 5: Average Annual Growth Rate of Output per Working Age Population

\begin{tabular}{rrrrr}
\hline & $E 1$ & $E 3$ & $E 5$ & $E 7$ \\
\hline $2015-2021$ & $0.17 \%$ & $1.18 \%$ & $0.61 \%$ & $1.58 \%$ \\
$2025-2060$ & $1.58 \%$ & $1.62 \%$ & $1.58 \%$ & $1.62 \%$ \\
\hline
\end{tabular}

To get a sense for how these policy changes would affect living standards, we show output per person in Figure 9. In all cases where income taxation is substituted for consumption taxation, the Japanese economy is predicted to enjoy considerable growth in income per capita relative to the benchmark starting in 2015 until date $T_{1}=202116$ After 2021, all cases grow at a similar rate, although living standards are permanently higher in the cases with higher growth beginning in 2015 .

The average growth rates for per capita income is shown in Table 5 for the initial years after the policy change (2015-2021) and for the years 2025-2060. In all cases, this growth rate is equal to $1.5 \%$ in the balanced growth path to which the model economy ultimately converges. The conclusion to be drawn from this table is that, according to this model, Japan could enjoy considerable growth in the short run by replacing income taxation with consumption taxation. In fact, the level of output in 2021 is $8.3 \%$ higher in experiment E3 than in the baseline E1. Similarly, output would be $8.5 \%$ higher in E5 and $14.8 \%$ higher in E7 when all income taxation is replaced with consumption taxation.

\footnotetext{
${ }^{16}$ The value of $T_{1}$ in E5 is 2022.
} 


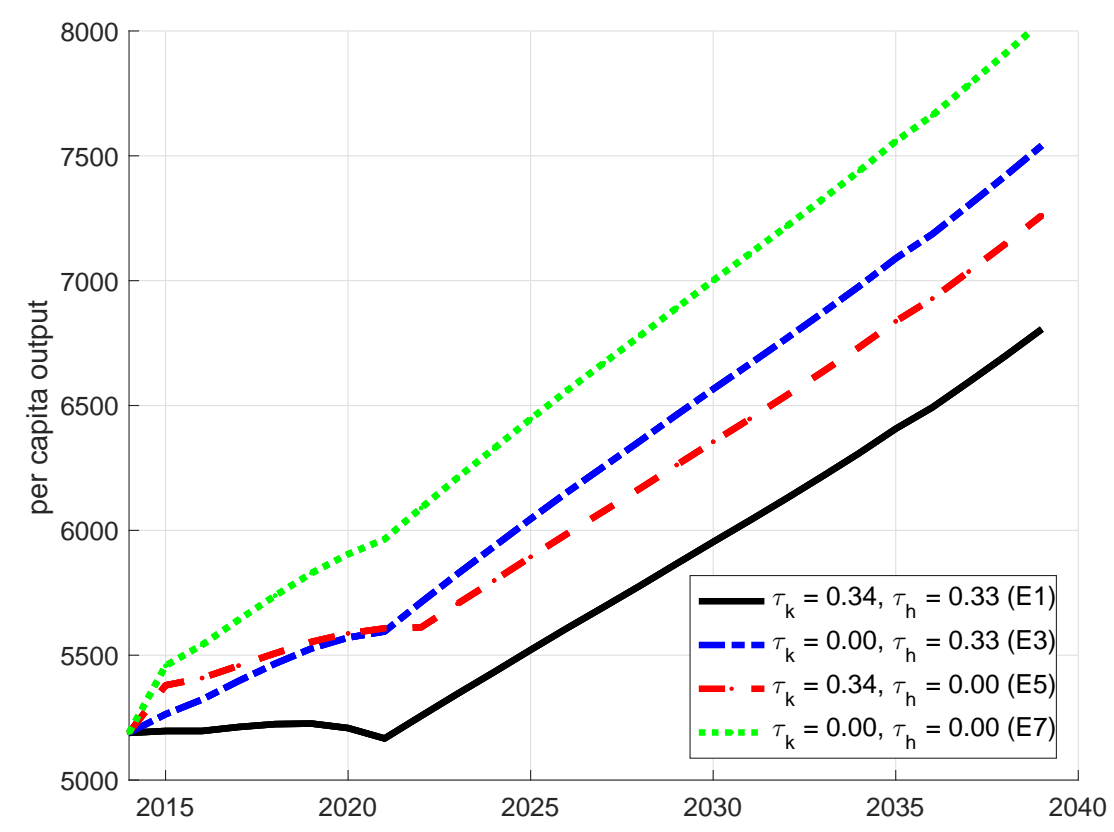

Figure 9: Output per Person

\subsubsection{Unanticipated Reform with a Delayed Increase in $\tau_{c}$}

In this subsection we consider how our results would change if Japan were to reduce income tax rates in 2015 without increasing $\tau_{c}$. Instead, any increase in the consumption tax is delayed until date $T_{1}$ and is set according to equation (2). Table 6 provides results from the same set of experiments reported on in Table 4. As the first line of this table shows, $\tau_{c}$ does not change from the benchmark in 2015. As a result, $T_{1}$, the date when the maximum debt to output ratio is reached, is a year or two earlier than the dates reported in Table 4. The main finding is that the tax increases required at $T_{1}$ are generally higher than in the previous case. 
Table 6: Unanticipated Reform with a Delay in $\tau_{c}$

\begin{tabular}{lrrrrrrr}
\hline & $E 1$ & $E 2$ & $E 3$ & $E 4$ & $E 5$ & $E 6$ & $E 7$ \\
\hline$\tau_{c, 2015}$ & 0.08 & 0.08 & 0.08 & 0.08 & 0.08 & 0.08 & 0.08 \\
$\tau_{2015}$ & 0.3818 & 0.3819 & 0.3819 & 0.2593 & 0.0741 & 0.2593 & 0.0741 \\
$T_{1}$ & 2021 & 2020 & 2020 & 2020 & 2019 & 2019 & 2018 \\
$\tau_{c, T_{1}}$ & 0.3760 & 0.3841 & 0.4438 & 0.5067 & 0.7287 & 0.5285 & 0.8052 \\
$\tau_{T_{1}}$ & 0.5148 & 0.5177 & 0.5376 & 0.4690 & 0.4215 & 0.4766 & 0.4460 \\
$T_{2}$ & 2084 & 2103 & 2122 & 2112 & 2084 & 2070 & 2073 \\
$\tau_{c, T_{2}}$ & 0.3160 & 0.3241 & 0.3438 & 0.4367 & 0.6287 & 0.4485 & 0.6752 \\
$\tau_{T_{2}}$ & 0.4927 & 0.4958 & 0.5032 & 0.4432 & 0.3860 & 0.4477 & 0.4031 \\
\hline
\end{tabular}

E1 : Benchmark, $\tau_{k, t}=0.3409$ and $\tau_{h, t}=0.3324$ for all $t \geq 2015$

$E 2: \tau_{k, t}=0.2$ and $\tau_{h, t}=0.3324$ for all $t \geq 2015$

$E 3: \tau_{k, t}=0$ and $\tau_{h, t}=0.3324$ for all $t \geq 2015$

$E 4: \tau_{k, t}=0.3409$ and $\tau_{h, t}=0.2$ for all $t \geq 2015$

$E 5: \tau_{k, t}=0.3409$ and $\tau_{h, t}=0$ for all $t \geq 2015$

$E 6: \tau_{k, t}=0.2$ and $\tau_{h, t}=0.2$ for all $t \geq 2015$

$E 7: \tau_{k, t}=0$ and $\tau_{h, t}=0$ for all $t \geq 2015$

$T_{1}$ : Date when $B / Y$ reaches $250 \%$.

$T_{2}$ : Date when $B / Y$ is less than or equal to steady state value.

$\tau_{c, t}$ : Consumption tax rate at date $t$.

$\tau_{t}=\left(\tau_{c, t}+\tau_{h, t}\right) /\left(1+\tau_{c, t}\right)$ Effective tax rate at date $t$.

$\pi$ in equation (2) equals $\tau_{c, T_{1}}-\tau_{c, T_{2}}$.

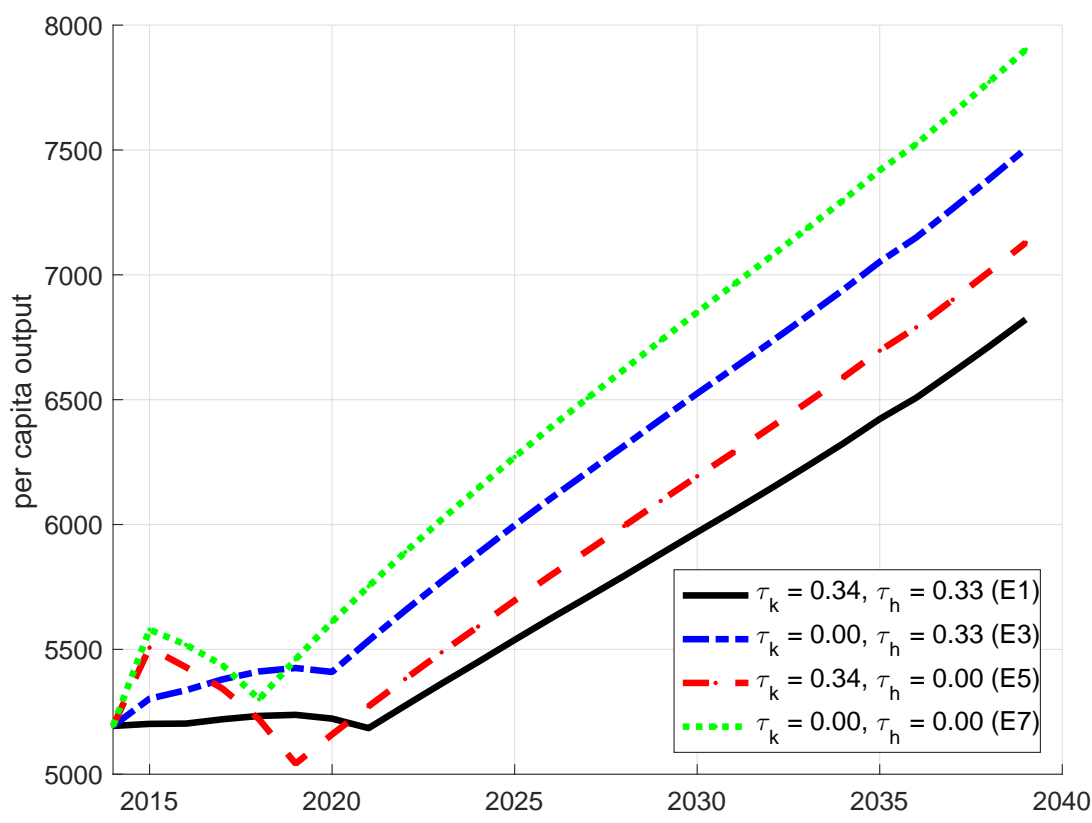

Figure 10: Output per Person 
Table 7: Average Annual Growth Rate of Output per Working Age Population

\begin{tabular}{rrrrr}
\hline & $E 1$ & $E 3$ & $E 5$ & $E 7$ \\
\hline $2015-2021$ & $0.17 \%$ & $0.93 \%$ & $-0.30 \%$ & $0.80 \%$ \\
$2025-2060$ & $1.58 \%$ & $1.64 \%$ & $1.64 \%$ & $1.67 \%$ \\
\hline
\end{tabular}

As can be seen from Table 7 and Figure 10, the growth benefits from tax reform are lower than in the case where the consumption tax rate is increased simultaneously with the reduction in income tax rates. In particular, output in 2021 in experiment E3 is 7.1\% higher than in the baseline (E1). In experiment E5, where only the labor tax is eliminated, output would be only $2 \%$ higher in 2021. In fact, as can be seen in both Table 7 and Figure 10, the growth rate of output per capita is negative in several of the years between 2015 and 2021. If all income taxes are eliminated, output would be $11.3 \%$ higher than in the baseline. These growth rates are lower here relative to the revenue neutral case because lower income taxes with knowledge that the consumption tax will be raised in the future leads to a temporary consumption boom that dampens the investment boom that these tax reforms otherwise trigger.

\subsection{Welfare Analysis}

In this section we compute welfare differences across experiments E1-E7. For each experiment E2-E7, we calculate the consumption equivalent variation (CEV) relative to our baseline experiment by calculating the percent change in consumption that would be required each period in experiment E1 to make the present discounted utility the same as in the alternative experiment.

To be more specific, let the realized discounted 1981 value of utility in experiment E1 be denoted by $\widehat{W}$. This can be calculated using the sequence of consumption, hours and bond holdings that are realized in experiment E1:

$$
\widehat{W}=\sum_{t=1981}^{\infty} \beta^{t} N_{t}\left[\log \widehat{C}_{t}-\alpha \frac{\widehat{h}_{t}^{1+1 / \psi}}{1+1 / \psi}+\phi \log \left(\mu_{t}+\widehat{B}_{t+1}\right)\right]
$$

Let $W$ be the corresponding realized utility for one of our alternative experiments. The CEV, $\lambda$, is the percentage change in consumption required in each period so that the augmented sequence realized in the benchmark transition E1 provides discounted utility equal to $W$. That is, $\lambda$ solves the following equation:

$$
W=\sum_{t=1981}^{\infty} \beta^{t} N_{t}\left[\log \left[(1+\lambda) \widehat{C}_{t}\right]-\alpha \frac{\widehat{h}_{t}^{1+1 / \psi}}{1+1 / \psi}+\phi \log \left(\mu_{t}+\widehat{B}_{t+1}\right)\right]
$$


Solving for $\lambda$ yields

$$
\lambda=\exp \left(\frac{W-\widehat{W}}{\sum_{t=1981}^{\infty} \beta^{t} N_{t}}\right)-1
$$

Table 8: Welfare Analysis: $\operatorname{CEV}(\lambda)$ Relative to Experiment 1

\begin{tabular}{lllrr}
\hline & \multicolumn{2}{c}{ For $t \geq 2015$} & $\lambda$ & $\lambda$ \\
& $\tau_{k, t}$ & $\tau_{h, t}$ & $(R$-neutral $)$ & $($ delay $)$ \\
\hline$E 1$ & 0.3409 & 0.3324 & - & - \\
$E 2$ & 0.20 & 0.3324 & 0.0090 & 0.0099 \\
$E 3$ & 0.0 & 0.3324 & 0.0196 & 0.0257 \\
$E 4$ & 0.3409 & 0.20 & 0.0047 & 0.0138 \\
$E 5$ & 0.3409 & 0.0 & 0.0111 & 0.0212 \\
$E 6$ & 0.20 & 0.20 & 0.0120 & 0.0144 \\
$E 7$ & 0.0 & 0.0 & 0.0309 & 0.0362 \\
\hline
\end{tabular}

In Table 8 we report the welfare gains associated with the transition paths for each experiment relative to our benchmark, E1. In particular, the fourth and fifth columns of the table provide the value of $\lambda$ for each of experiments we have considered. Three patterns from this table are worth noting. First, the welfare gains are strictly higher in each experiment if the consumption tax increase is delayed until the fiscal trigger is activated (date T1). This reflects the role of discounting and may also reflect that, if the increase in $\tau_{c}$ is delayed, it is anticipated when the unanticipated tax reform is introduced in 2015. An implication of this may be that to delay planned consumption tax increases in spite of reducing tax rates on capital income, as Japan has done twice, is not problematic from the perspective of our model.

The second pattern is that the welfare gains from reducing $\tau_{k}$ are generally larger than those from reducing $\tau_{h}$. For example, in the revenue neutral case, the welfare gains from reducing $\tau_{k}$ to 0.2 and leaving $\tau_{h}$ unchanged (experiment E2) are about twice as large as the gains from leaving $\tau_{k}$ unchanged and reducing $\tau_{h}$ to 0.2 (experiment E4). Finally, significant welfare gains-more than 3\%-are possible by eliminating all income taxation in favor of consumption taxation (experiment E7). 


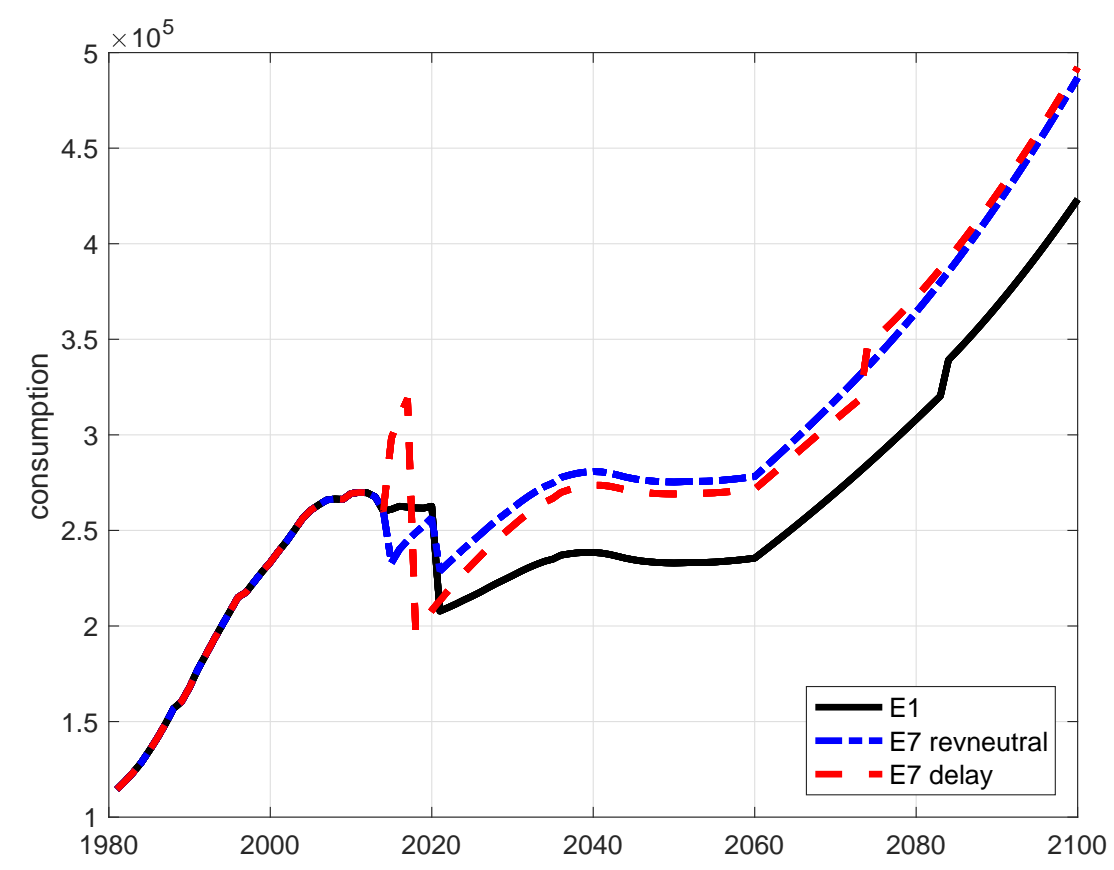

Figure 11: Consumption

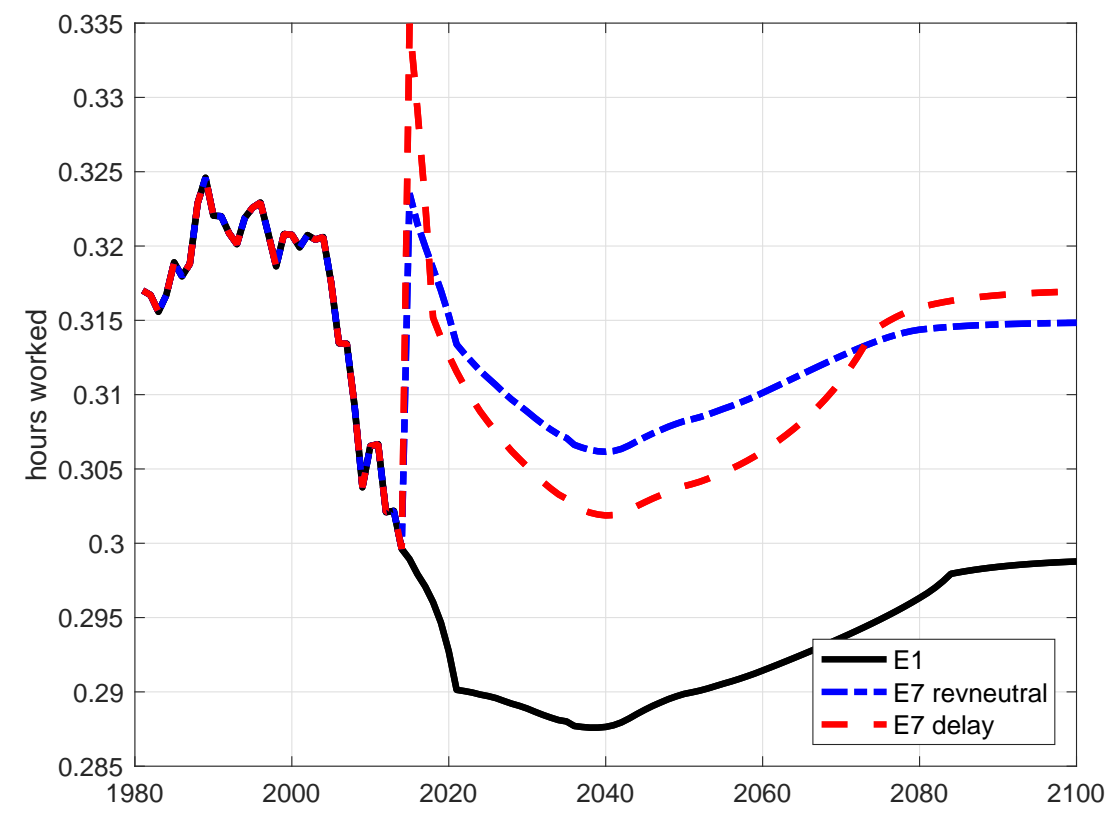

Figure 12: Hours Worked

\section{Conclusion}

Japan's policymakers have recently reduced the effective corporate income tax rate in an effort to generate higher investment and output. In this paper we use a neoclassical growth 
model that builds on Hayashi and Prescott (2002), Chen, İmrohoroğlu, and Imrohoroğlu (2006), and Hansen and Imrohoroğlu (2016) to measure the effects of replacing income taxation with consumption taxation on Japan's economy. Our model is a one sector deterministic growth model in which the private sector has perfect foresight about population growth rates, government policy and factor prices. Both the quantity and the price of bonds are endogenously determined in our model; government purchases of goods and services and transfer payments are exogenous. The government raises revenue by taxing factor incomes, interest income and consumption. The representative household values consumption, leisure, and government bonds and markets are complete. By including bonds in the utility function, the model is made consistent with the very strong domestic demand for government bonds in Japan.

Our focus on this paper is an unanticipated tax reform that takes place in 2015. That is, from the beginning (1981), agents in our model anticipate the tax changes that will happen when the debt to output ratio reaches the critical level. They do not, however, anticipate the movement away from income taxation that we implement in 2015. We then compare the welfare and growth consequences of these unanticipated changes relative to what would happen without such a reform.

We consider two different ways of implementing a policy that reduces income taxes in 2015. First, we assume that the consumption tax rate rises at the beginning of 2015 in order to replace the lost revenue associated with the income tax rate reduction; we label these experiments 'revenue-neutral'. In the second set of experiments, no increase in the consumption tax is implemented in 2015, which we call 'delayed increase' because the government is assumed to delay any increase in the consumption tax until the debt to output trigger is reached. Our 'delayed increase' experiments seem closer to actual Japanese government's tax reform policy compared to the 'revenue-neutral' experiments 17

After calibrating the model to the Japanese economy, we compute transition paths from observed initial conditions in Japan in 1981 to a steady-state in the distant future. Relative to maintaining income tax rates at the 2014 levels, reductions in either the labor or capital income tax (with a higher consumption tax rate to replace lost revenues) produce significant gains in labor supply or investment in the short run, with the gains higher when both income taxes are reduced. These growth effects are larger in the 'revenue-neutral' experiments.

Our welfare analysis indicates that there are significant gains from reducing income taxation, more than $3 \%$ if all income taxation is eliminated. These welfare gains are generally larger from reducing the tax on capital income than those from reducing the labor income tax rate.

Finally, the welfare gains are strictly higher in each experiment if the consumption tax increase is delayed until the fiscal trigger is activated. In other words, our growth effects

\footnotetext{
${ }^{17}$ As of September 2017, the actual government policy is close to our 'delayed increase' policy in the following two aspects: (i) The increase in the consumption tax rate and the decrease in corporate tax rate have not gone hand in hand so far. The consumption tax rate was not raised to $10 \%$ as scheduled, and the timing of the rise was postponed, while the corporate tax rate was reduced as scheduled. (ii) The rise of the consumption tax rate and fiscal consolidation going forward explicitly are both committed to by the government. Note also, however, that the actual government policy is different from the 'delayed increase' policy as it is not explicit in details as to when and how the consolidation is going to be attained.
} 
favor the revenue-neutral experiments that call for an immediate rise in the consumption tax rate when income taxation is reduced, but our welfare findings suggest that delaying this increase in the consumption tax may be better from the point of view of welfare analysis. This reflects the role of discounting and the fact that even when the consumption tax increase is delayed it is still fully anticipated to take place in the near future when the unanticipated tax reform is introduced in 2015. 


\section{References}

Aiyagari, S. R. and E. R. McGrattan (1998). The optimum quantity of debt. Journal of Monetary Economics 42(3), 447-469.

Arnold, J. (2008). Do tax structures affect aggregate economic growth? empirical evidence from a panel of OECD countries. Working Paper.

Barro, Robert, J. (1990). Government spending in a simple model of endogeneous growth. Journal of Political Economy 98(55), 103-125.

Buera, F., B. Moll, and Y. Shin (2013). Well-intended policies. Review of Economic Dynamics 16(1), 216-230.

Caballero, R., T. Hoshi, and A. Kashyap (2008). Zombie lending and depressed restructuring in japan. American Economic Review 98(5), 1943-1977.

Chamley, C. (1986). Optimal taxation of capital income in general equilibrium with infinite lives. Econometrica 54(3), 607-622.

Chen, K., A. İmrohoroğlu, and S. İmrohoroğlu (2006). The Japanese saving rate. American Economic Review 96(5), 1850-1858.

Chetty, R., A. Guren, D. Manoli, and A. W. Broda (2012). Does indivisible labor explain the the difference between micro and macro elasticities? a meta-analysis of extensive margin elasticities. In D. Acemoglu, J. Parker, and M. Woodford (Eds.), NBER Macroeconomics Annual, pp. 1-56. Massachusetts: The University of Chicago Press.

Easterly, W. and S. Rebelo (1993). Fiscal policy and economic growth: An empirical investigation. Journal of Monetary Economics 32(3), 417-458.

Fukawa, T. and I. Sato (2009). Projection of pension, health and long-term care expenditures in Japan through macro simulation. The Japanese Journal of Social Security Policy 8(1), 33-42.

Guner, N., G. Ventura, and X. Yi (2008). Macroeconomic implications of size-dependent policies. Review of Economic Dynamics 11(4), 721-744.

Gunji, H. and K. Miyazaki (2011). Estimates of average marginal tax rates on factor incomes in Japan. Journal of the Japanese and International Economies 25(2), 81106.

Hansen, G. and S. İmrohoroğlu (2016). Fiscal reform and government debt in Japan: A neoclassical perspective. Review of Economic Dynamics 21 (July), 201-224.

Hayashi, F. and E. C. Prescott (2002). The 1990s in Japan: A lost decade. Review of Economic Dynamics 5(1), 206-235.

Hoshi, T. and T. Ito (2014). Defying gravity: Can the Japanese soveriegn debt continue to increase without a crisis? Economic Policy 29(77), 5-44.

İmrohoroğlu, S., S. Kitao, and T. Yamada (2016). Achieving fiscal balance in Japan. International Economic Review 57(1), 117154.

Judd, K. L. (1985). On the performance of patents. Econometrica 53(3), 567-586. 
Knellera, R., M. F. Bleaney, and N. Gemmell (1999). Fiscal policy and growth: evidence from OECD countries. Journal of Public Economics 74 (2), 171-190.

Kwon, H. U., F. Narita, and M. Narita (2015). Resource reallocation and zombie lending in Japan in the 1990s. Review of Economic Dynamics 18(4), 709-732.

Mendoza, E. G., G. M. Milesi-Ferretti, and P. Asea (1997). On the ineffectiveness of tax policy in altering long-run growth: Harberger's superneutrality conjecture. Journal of Public Economics 66(1), 99-126.

Nakajima, T. and S. Takahashi (2017). Optimum quantity of debt in Japan. Understanding Persistent Deflation in Japan Working Paper Series No. 093.

Nutahara, K. (2015). Laffer curves in Japan. Journal of the Japanese and International Economies 36(C), 56-72.

Sakuragawa, M. and K. Hosono (2010). Fiscal sustainability of japan: A dynamic stochastic general equilibrium approach. The Japanese Economic Review 61(4), 517-537.

Trabandt, M. and H. Uhlig (2011). The laffer curve revisited. Journal of Monetary Economics 58(4), 305-327. 